\title{
The role of organic carbon, iron, and aluminium oxyhydroxides as trace metal carriers: Comparison between the Trinity River and the Trinity River Estuary (Galveston Bay, Texas)
}

\author{
Liang-Saw Wen ${ }^{\text {a }}$, Kent W. Warnken ${ }^{\mathrm{b}}$, Peter H. Santschi ${ }^{\mathrm{c}, *}$ \\ a Institute of Oceanography, National Taiwan University, Taipei, Taiwan \\ b Thermo Fisher Scientific, 4410 Lottsford Vista Rd., Lanham MD 20706, USA \\ c Texas AEM University at Galveston, Departments of Marine Sciences and Oceanography, Laboratory for Oceanographic and Environmental Research (LOER), \\ 5007 Ave U, Galveston, Texas, 77551, USA
}

\section{A R T I C L E I N F O}

\section{Article history:}

Received 2 January 2008

Received in revised form 5 June 2008

Accepted 20 June 2008

Available online 18 July 2008

\begin{abstract}
A B S T R A C T
Concentrations of many trace elements in aquatic systems can become enriched due to anthropogenic as well as natural processes. In order to investigate particle enrichment processes from the river through an estuary, the changes in solid phase speciation and particle-water partitioning of a number of trace metals (e.g., Fe, $\mathrm{Pb}, \mathrm{Cd}, \mathrm{Cu}, \mathrm{Ni}, \mathrm{Zn}, \mathrm{Co}, \mathrm{V}$ ) were evaluated from the Trinity River through Galveston Bay to the Ocean. An established way to detect anthropogenic contamination is by normalization of contaminant concentrations to $\mathrm{Fe}, \mathrm{Al}$, and/or organic carbon (OC). Particulate metal ( $\mathrm{Mn}, \mathrm{Co}, \mathrm{Ni}, \mathrm{Cu}, \mathrm{Pb}, \mathrm{V}, \mathrm{Ni}, \mathrm{Zn}, \mathrm{Cd}$ ) to Fe, $\mathrm{Al}$, and metal to OC ratios were determined in waters of the Trinity River and Galveston Bay, in order to test 1 ) if the system is contaminated, and 2) whether $\mathrm{Fe}, \mathrm{Al}$, or organic carbon act as a master variable for determining metal concentrations. All particulate trace metals from Trinity River were present in ratios to $\mathrm{Fe}$ or $\mathrm{Al}$ similar to those from drainage basin soils, which were similar to world worldaverage soil. As expected, concentrations of $\mathrm{Fe}, \mathrm{Al}$ and $\mathrm{OC}$ in particles from both the Trinity River as well as Galveston Bay were strongly correlated, from which one might conclude that Fe can be used as a reference element that is representative for all three of them. However, ratios to Fe of particle-reactive elements, such as $\mathrm{Pb}$, were found to be significantly and positively correlated to the Fe content of particles from Galveston Bay, while nutrient-type elements, such as $\mathrm{Cu}, \mathrm{Ni}$, and $\mathrm{Cd}$, were negatively correlated to their Fe content. Interestingly, suspended particles from the Trinity River did not exhibit any such correlations at all and only varied within a very limited range. The reason for such distinctive correlative behavior that distinguishes riverine from estuarine particles is likely caused by internal cycling of these elements within Galveston Bay, and their relationship to OC. Relationships of trace metals to OC revealed that differences in sources and cycling of $\mathrm{OC}$ in the estuary significantly altered the soil imprinted particle make-up. Results from selective leaching experiments of suspended particles in Galveston Bay confirmed the selective enrichment and fractionation processes for the different metals.
\end{abstract}

(c) 2008 Elsevier B.V. All rights reserved.

\footnotetext{
* Corresponding author. Tel.: +1 4097404476. E-mail addresses: Iswen@ntu.edu.tw (L.-S. Wen), kentwarnken@hotmail.co.uk (K.W. Warnken), santschi@tamug.edu (P.H. Santschi).
}

\section{Introduction}

Many trace metals in natural waters are often associated with either iron oxyhydroxides or with humic type natural organic matter (NOM), both of which are often also associated with clay minerals, i.e., Al. Examples for metal partitioning related to iron and organic rich particles include $\mathrm{Pb}$ (Wen 
et al., 1999; Taillefert et al., 2000; Mondi et al., 2002), Ag (Wen et al., 1997a, 2002), and Pu (Santschi et al., 2002; Novikov et al., 2006). A few studies observed that a trace metal, i.e., Pb, is directly bound to colloidal Fe Fe-oxyhydroxides that are stabilized by an organic matrix (e.g., Taillefert et al., 2000; Lyven et al., 2003).

Even though in oxic aquatic systems, iron occurs mostly in the particulate phase, and only a small and colloidal fraction of it can pass a $0.45 \mu \mathrm{m}$ filter, it is this micro- and nanoparticulate, i.e., colloidal, fraction that is the most mobile in surface waters, while the macro-particles are subject to gravity, and are rapidly removed from an aquatic system. There appear to be two main kinds of colloids in fresh and near-shore marine waters: an iron iron-rich (with sizes ranging from $2-3 \mathrm{~nm}$ to $100 \mathrm{~s}$ of $\mathrm{nm}$ ) and a humic acid rich (with a size of 1-2 nm) colloid (e.g., Wen et al., 1999; Lyven et al., 2003). However, even the iron iron-rich colloid contains a certain amount of NOM to render it negatively charged, as without NOM it would be uncharged at near-neutral $\mathrm{pH}$ values and thus, would rapidly coagulate and sediment out. The close association of iron-rich colloids in groundwater with NOM has recently been convincingly depicted for groundwater using analytical electron microscopy (Mondi et al., 2002).

Generally, there is a decreasing trend in Fe to organic carbon (OC) ratios from particles to colloids, and from colloids in surface waters to groundwaters to estuarine to oceanic waters, as evident from Fig. 1. This indicates that despite the negative charge from associated OC, Fe is becoming preferentially altered at environmental interfaces. Because both $\mathrm{Fe}$ oxides (or sulfides) and NOM compounds can sequester trace metals from both dissolved and colloidal forms, the question arises if trace metals are removed by Fe or OC compounds.

Most of the iron in surface waters is present as iron oxyhydroxides, and to some extent, as iron sulfides and iron silicates. Surface adsorbed iron would be expected to be a minor fraction in oxic waters. However, at redox fronts near a sediment-water interface or in groundwaters, where iron hydroxides can get reduced and remobilized by OC-driven reactions, the partitioning and reactivity of Fe and associated elements in the oxic part of the interface would likely show the imprint of these redox process, and reveal more reactive phases such as surface adsorbed and Fe/Mn Mn-oxyhydroxide phases.

It is believed that most dissolved trace metals $(<0.4 \mu \mathrm{m})$ are biologically accessible. In order to gain insight into the potential bioavailability of suspended particles and sediments, sequential extraction techniques can be applied to differentiate between surface exchangeable, carbonatebound, reducible (hydrous Fe/Mn oxides), oxidizable (sulfides and organic phases), and refractory phases (Tessier et al., 1979; Kersten and Forstner, 1986). Despite clear advantages of a more differentiated analytical approach, as sequential chemical extraction provides for a tool for predicting adverse effects from solid materials, it has been heavily criticized for conceptual and analytical problems associated with these procedures (Thompson, 1980; Kersten and Forstner 1987; Rapin et al., 1986; Martin et al., 1987). However, recent work on solid speciation of marine suspended particles, which employed ultra-clean techniques seem to have overcome many of the analytical biases and have shown promise for elucidating the reactivity of trace metals in suspended solid phases (Landing and Lewis, 1991; Koschinsky et al., 2001).
Correlations of trace metal concentrations in sediments with those of $\mathrm{Fe}, \mathrm{Al}$ or $\mathrm{OC}$ can be used to shed light on natural or anthropogenic enrichment processes. Normalization of trace metal concentrations to $\mathrm{Fe}$ and/or $\mathrm{Al}$ has therefore become an accepted practice in environmental science for evaluating elevated trace metal levels in natural waters due to anthropogenic activities (e.g., Windom et al., 1988, 1989; Summers et al., 1996).

Many trace metals strongly interact with specific organic ligands, and it is believed that NOM cycling and differences in its sources have a profound effect on the cycling of most trace metals. The effects of dissolved organic carbon (DOC) and particulate organic carbon (POC) cycling in riverine and estuarine environments on trace metal cycling is, however, less well documented than that of specific ligands that make up only a small fraction of DOC and POC concentrations, e.g., thiols to $\mathrm{Cu}$ (e.g., Tang et al., 2001).

The concentrations of DOC in the Trinity River are positively correlated to Trinity River flow rates (Warnken and Santschi, 2004), except for times of first rain of the season and tropical storms. POC concentration was also linearly correlated to Trinity River flow rates, while the OC content of the particles decreases non-linearly from $10-12 \%$ at low discharge rates to only $1-2 \%$ at higher discharge rates, likely resulting from the dilution of smaller carbon-rich particles at low flow by larger, organic carbon-poorer particles that are resuspended at higher flow rates (Warnken and Santschi, 2004).

Carbon loading of Galveston Bay was estimated using organic carbon flux vs. discharge relationships with the total organic carbon load (TOC) of $1.1 \times 10^{8} \mathrm{~kg} \mathrm{C} \mathrm{OC} \mathrm{yr}^{-1}$. Comparison of river flux of DOC to in-situ measured DOC benthic fluxes indicates that the sediments can contribute $\sim 20 \%$ of the DOC loading of Trinity Bay at medium to high flow rates, while during low-flow conditions, the sediments can contribute $>80 \%$ of the DOC inputs to Galveston Bay (Warnken and Santschi, 2004).

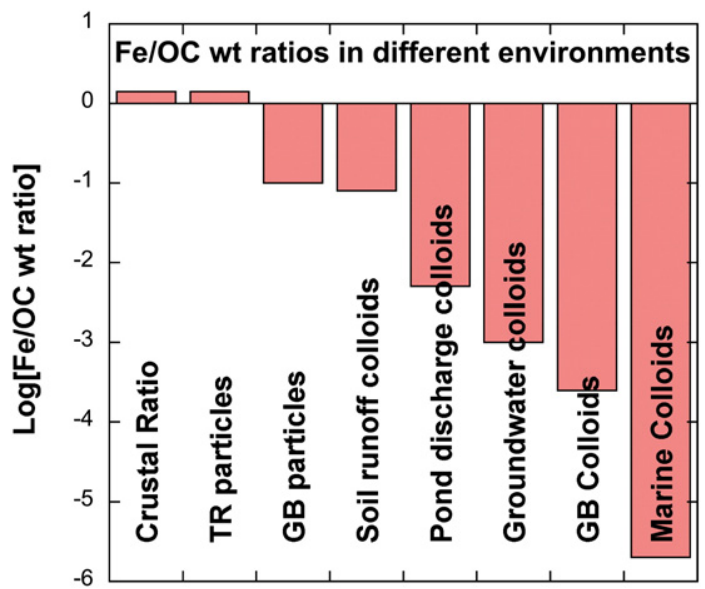

Fig. 1. Typical Fe/OC ratios in different environmental compartments. Crustal ratios are from Li (2000), surface water runoff and pond discharge colloid ratios from Santschi et al. (2002), ratios for groundwater colloids from Robert et al. (2004), and ratios for estuarine and marine colloids from Wen et al. (1999) and Guo et al. (2000). GB = Galveston Bay; TR = Trinity River. 
Measurements of $\Delta^{14} \mathrm{C}$ and $\mathrm{C} / \mathrm{N}$ ratios in colloidal organic matter $\geq 1 \mathrm{kDa}\left(\mathrm{COM}_{1}\right)$, which makes up the majority of DOC in freshwater and estuarine environments, revealed that, in general, riverine water $\mathrm{COM}_{1}$ contains higher (i.e., modern) $\Delta{ }^{14} \mathrm{C}$ values and higher $\mathrm{C} / \mathrm{N}$ ratios that are steadily decreasing as river water mixes with seawater, with consistently higher values for both than in colloidal organic matter $\geq 10 \mathrm{kDa}, \mathrm{COM}_{10}$ (Guo and Santschi, 1997a). Decreasing $\Delta^{14} \mathrm{C}$ values and $\mathrm{C} / \mathrm{N}$ ratios in $\mathrm{COM}$ in the estuarine mixing zone were attributed to sedimentary inputs of COM. In pelagic environments, the age difference between $\mathrm{COM}_{10}$ and $\mathrm{COM}_{1}$ is the opposite from that in benthic nepheloid layer and estuarine environments (Guo and Santschi, 1997b). The distinct difference in isotopic signature and elemental composition between river-influenced and lower estuarine DOM suggest that a substantial fraction of the riverine DOM is likely removed or decomposed during estuarine mixing. The composition of $d^{13} \mathrm{C}$ of $\mathrm{COM}_{1}$ in July 1995 , for example ( $\sim 28$ to $-25 \%$ ), steadily increasing above a salinity of 20 to seawater values ( -21\%) (Guo et al., 2003), indicates distinct regions in Galveston that are strongly influenced either by terrestrial (allochthonous) or freshly produced (autochthonous) organic matter.

Colloidal iron concentrations, at certain times, decrease immediately upon mixing Trinity River water into upper Galveston Bay, after which they stay constant (Wen et al., 1999), while all other colloidal trace metals (e.g., $\mathrm{Al}, \mathrm{Mn}, \mathrm{Cu}$, $\mathrm{Co}, \mathrm{Ni}, \mathrm{Pb}, \mathrm{Cd}, \mathrm{Zn}$ ) decrease more slowly through Galveston Bay (Wen et al., 1999). Complexation with reduced sulfur species was important for the organic complexation of dissolved and colloidal $\mathrm{Cd}, \mathrm{Cu}, \mathrm{Ni}, \mathrm{Pb}$ and $\mathrm{Zn}$ in Galveston Bay, as evidenced by linear correlations between particulate and filter-passing metal concentrations and reduced sulfur species (Tang et al., 2002). Thus, it might be expected that POC, as well as reduced sulfur compounds, should exert similar controls on particulate trace metal distributions.

In this paper, we will investigate particulate metal to $\mathrm{Fe}, \mathrm{Al}$, and $\mathrm{OC}$ ratios in waters of the Trinity River and Galveston Bay for three purposes: 1) to determine if the system is contaminated; 2) to determine if $\mathrm{Fe}, \mathrm{Al}$, or $\mathrm{OC}$ act as a master variable for metal accumulation; and 3) to investigate differences between particlereactive (e.g., $\mathrm{Fe}, \mathrm{Al}, \mathrm{Pb}$ ) and nutrient-type (e.g., $\mathrm{Cu}, \mathrm{Ni}, \mathrm{Zn}, \mathrm{Cd}$ ) elements (Bruland, 1983) in their correlative behavior. Solid phase speciation experiments of trace metals can be used to probe the hypothesis that alteration of the particle make-up from the Trinity River through Galveston Bay to the Ocean is due to gains of OC by primary productivity and loss of clay minerals and iron oxides to sediments in the low salinity end of the estuary.

The aim of our study is thus to provide a better understanding of the mechanisms and processes, which affect metal-particle associations and their dynamics in estuarine, coastal and marine environments. It complements investigations of dissolved and colloidal trace metal distributions in Galveston Bay, which were carried out at the same time but reported earlier (Wen et al., 1999), as well as investigations of OC (Warnken et al., 2008) and trace metal fluxes from the Trinity River to Galveston Bay (Warnken and Santschi, in press). These studies demonstrated that significant fractions of trace metals occur in the colloidal state (Wen et al., 1999), and trace metal fluxes show a large decrease when passing through Lake Livingston, and then again through Galveston Bay (Jiann, 1999; Warnken and Santschi, in press).

\section{Materials and methods}

\subsection{Study sites}

The entire Trinity River watershed, shown in Fig. 2, encompasses some 33,000 mile $^{2}\left(84,500 \mathrm{~km}^{2}\right)$ or about $12.6 \%$ of the surface area of Texas, and is typically divided into an upper and lower region (GBNEP, 1994). Six man-made lakes in the upper watershed were constructed to provide flood control, supply drinking water and for recreational needs. A seventh exceptionally large reservoir, Lake Livingston, provides a final repository for most of the suspended solids transported through the upper watershed and removes about $60 \%$ of the phosphorus and 30\% of the nitrogen (GBNEP, 1994). Therefore, the lower watershed, downstream of Lake Livingston, acts as a more direct contributor of runoff and runoff-borne trace elements and pollutants to Galveston Bay than does the upper watershed. Soils associated with this lower watershed are comprised of clays and sands with low permeability and percolation rates and high runoff potential (GBNEP, 1994).

The Trinity River is the main freshwater input source to Galveston Bay, and is contributing, on average, approximately $83 \%$ of the gauged input (GBNEP, 1994). Rainfall occurs as thunderstorms during spring and summer, often associated with the passage of fronts during winter and with deluges associated with Tropical Storms and Hurricanes. Because precipitation can occur in different parts of the Trinity River watershed, often interrupted by long drought periods that can last greater than 6 months, river discharge rates can be very dynamic and can vary by two orders of magnitude (e.g., Warnken and Santschi, 2004, in press). Galveston Bay receives approximately $60 \%$ of the state's wastewater discharge.

During this study, 24 discrete samples were collected under various flow conditions of the Trinity River (i.e., 32$2033 \mathrm{~m}^{3}$ /s; Warnken and Santschi, 2004) during the years 2000-2001, beginning September 2000 through August 2001. The mean daily Trinity River discharge rate for the sampling period was $395 \mathrm{~m}^{3} \mathrm{~s}^{-1}$, slightly higher than that the average for the 1990s of $327 \mathrm{~m}^{3} \mathrm{~s}^{-1}$ (Warnken and Santschi, 2004).

The lower region of the Trinity River drainage basin has a relatively large upstream sink (Lake Livingston) just to the north, has no additional tributary inputs and is located in close proximity to Galveston Bay. Therefore, it is likely that variations in dissolved constituent concentrations will arise from hydrologic and in-situ biologic control and not from variations in upstream point source inputs. A number of parameters were obtained, including ancillary parameters (temperature, conductivity, dissolved oxygen and $\mathrm{pH}$ ), nutrients (phosphate, silicate, ammonium, nitrite, nitrate, urea), $\mathrm{DOC}$, and several trace metals ( $\mathrm{Al}, \mathrm{V}, \mathrm{Mn}, \mathrm{Fe}, \mathrm{Co}, \mathrm{Ni}, \mathrm{Cu}, \mathrm{Ag}, \mathrm{Cd}$, $\mathrm{Pb})$. Fluxes of $\mathrm{OC}$ and trace metals have been evaluated in Warnken and Santschi (2004, in press).

Two transects of Galveston Bay (Fig. 2) were sampled in July 20, 1993 and July 21, 1995 for dissolved and particulate metals ( $\mathrm{Al}, \mathrm{Fe}, \mathrm{Mn}, \mathrm{Cu}, \mathrm{Cd}, \mathrm{Ni}, \mathrm{Pb}, \mathrm{Zn}$ ), as well as for POC, DOC, suspended particulate matter (SPM) concentrations. According to USGS (2007), the Trinity River discharge rates at the time of sampling were about $135 \mathrm{~m}^{3} / \mathrm{s}$ (and up to $600 \mathrm{~m}^{3} / \mathrm{s}$ 1-2 weeks before) during the 1993 sampling expedition, and were about $100 \mathrm{~m}^{3} / \mathrm{s}$ during the 1995 sampling. Nutrient inputs from the Trinity River into Galveston Bay were also higher in 


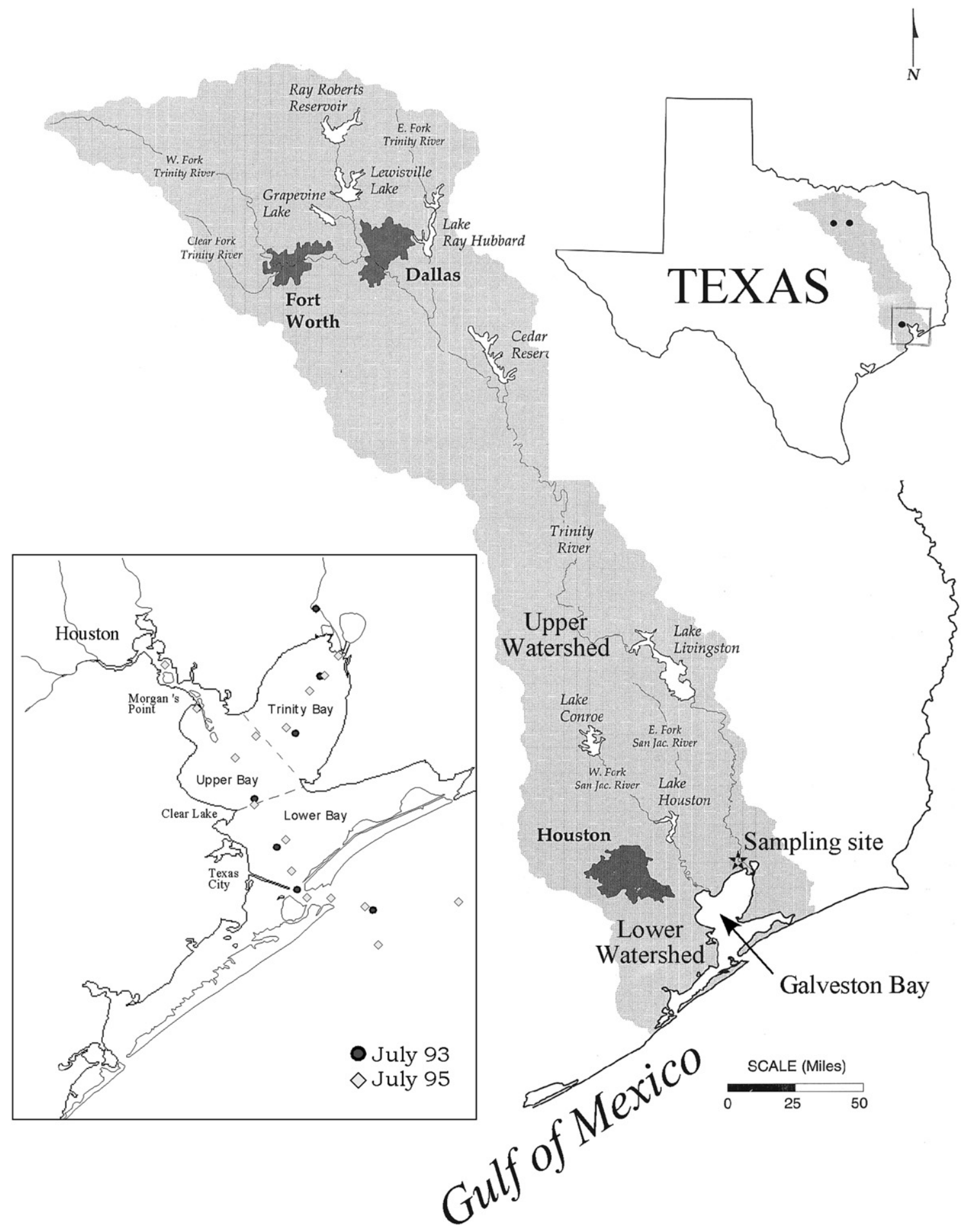

Fig. 2. Map of the sampling stations in the Galveston Bay estuary on July 20, 1993 and July 21, 1995; and the Trinity River drainage basin including Lake Livingston, which divides the region into an upper and lower watershed. The sampling site on the Trinity River, located in the lower drainage basin, is denoted by the star and is representative of the flow into Trinity Bay, which is the upper most region of Galveston Bay (modified from GBNEP, 1994).

1993 (USGS, 2007; Wen et al., 1997a, 1999). Concentrations of suspended particles (SPM), POC, and DOC in 1993 decreased with increasing salinity in a concave fashion, indicating net removal, while in 1995, distributions of these parameters first increased in the upper Galveston Bay, indicating net addition to the water column from the sediments (Wen et al., 1997a, 1999), before they decreased drastically in lower Galveston Bay. Results of distributions of dissolved and colloidal metals, and 
Table 1

Analytical blanks for the sequential leaching procedure of $47 \mathrm{~mm}, 0.45 \mu \mathrm{m}$ Nuclepore polycarbonate filters

\begin{tabular}{|c|c|c|c|c|c|c|}
\hline \multirow[b]{4}{*}{ Elements } & \multicolumn{2}{|l|}{$4.5 \mathrm{~N} \mathrm{Q}-\mathrm{HAc}$} & \multicolumn{2}{|c|}{$2 \mathrm{~N} \mathrm{Q}-\mathrm{HCl} / 1 \mathrm{~N} \mathrm{Q}-\mathrm{HNO}_{3}$} & \multicolumn{2}{|c|}{$\mathrm{Q}-\left(\mathrm{HCl} / \mathrm{HNO}_{3} / \mathrm{HF}\right)$} \\
\hline & Reagent & Filter & Reagent & Filter & Reagent & Filter \\
\hline & Mean \pm S.D. & Mean \pm S.D. & Mean \pm S.D. & Mean \pm S.D. & Mean \pm S.D. & Mean士S.D. \\
\hline & $n=6,(\mu \mathrm{g} / \mathrm{L})$ & $n=6,(\mu \mathrm{g} / \mathrm{g})$ & $n=6,(\mu \mathrm{g} / \mathrm{L})$ & $n=6,(\mu \mathrm{g} / \mathrm{g})$ & $n=6,(\mu \mathrm{g} / \mathrm{L})$ & $n=6,(\mu \mathrm{g} / \mathrm{g})$ \\
\hline$\overline{\mathrm{Al}}$ & $0.220 \pm 0.020$ & $0.045 \pm 0.032$ & $0.155 \pm 0.080$ & $0.533 \pm 0.148$ & $0.110 \pm 0.120$ & $0.225 \pm 0.045$ \\
\hline $\mathrm{Fe}$ & $0.160 \pm 0.025$ & $0.456 \pm 0.270$ & $0.150 \pm 0.020$ & $0.424 \pm 0.109$ & $0.230 \pm 0.060$ & $0.462 \pm 0.340$ \\
\hline $\mathrm{Mn}$ & $0.010 \pm 0.010$ & $0.039 \pm 0.006$ & $0.040 \pm 0.015$ & $0.122 \pm 0.071$ & $0.035 \pm 0.025$ & $0.186 \pm 0.071$ \\
\hline $\mathrm{Cd}$ & $<0.005$ & $0.520 \pm 0.148$ & $<0.005$ & $0.193 \pm 0.077$ & $0.015 \pm 0.005$ & $0.180 \pm 0.032$ \\
\hline Co & $0.030 \pm 0.015$ & $0.032 \pm 0.013$ & $0.035 \pm 0.005$ & $0.096 \pm 0.032$ & $0.010 \pm 0.015$ & $0.116 \pm 0.039$ \\
\hline $\mathrm{Cu}$ & $0.010 \pm 0.005$ & $0.449 \pm 0.019$ & $0.030 \pm 0.005$ & $0.276 \pm 0.026$ & $0.055 \pm 0.030$ & $0.083 \pm 0.064$ \\
\hline $\mathrm{Ni}$ & $0.070 \pm 0.035$ & $0.077 \pm 0.039$ & $0.010 \pm 0.010$ & $0.058 \pm 0.039$ & $0.015 \pm 0.025$ & $0.083 \pm 0.039$ \\
\hline $\mathrm{Pb}$ & $<0.005$ & $0.058 \pm 0.013$ & $0.030 \pm 0.020$ & $0.045 \pm 0.019$ & $0.050 \pm 0.015$ & $0.096 \pm 0.026$ \\
\hline $\mathrm{Zn}$ & $0.120 \pm 0.015$ & $0.597 \pm 0.218$ & $0.040 \pm 0.015$ & $0.193 \pm 0.128$ & $0.080 \pm 0.035$ & $0.578 \pm 0.128$ \\
\hline
\end{tabular}

some of the ancillary data, have been reported previously by Wen et al. (1997a, 1999) and Guo et al. (2000). Trinity River loads of organic carbon and trace metals to Galveston Bay and the Ocean are described by Warnken and Santschi (2004), Warnken et al. (2008) and Warnken and Santschi (in press).

\subsection{Field sampling}

Trinity River samples were collected near the Interstate Highway-10 ( $\mathrm{IH}-10$ ) bridge overpass due to its location in the lower watershed, the close proximity of this site to the river mouth (end-member representation) and the easy access to the river (Fig. 2).

Surface water samples from Galveston Bay were collected along a salinity gradient ranging from 0 to 35 during July of 1993 and July 1995 (Fig. 2). In short, Nuclepore filters $(0.45 \mu \mathrm{m})$ were loaded in Teflon filter assemblages (Savellex) to collect particles in-situ. After sample collection, the filter assemblages were placed in double acid cleaned plastic bags, placed on ice, returned to the laboratory, refrigerated and kept in the dark until further processing. The details of the ultra-clean sampling protocol as well as clean procedures for pre-cleaning, sampling, processing and analyzing trace metals were reported previously (Wen et al., 1996, 1997a, 1999; Warnken et al., 2001; Tang et al., 2001, 2002).

\subsection{Sample processing and analysis}

Upon return to the TAMUG clean lab, $0.45 \mu \mathrm{m}$ filters were downloaded immediately, placed in acid cleaned petri dishes in the class-100 clean bench to air dry, re-weighed to determine the mass concentration, and put in the freezer until further processing. Within one month after sampling, particles residing on weighted filters were then leached or digested using a slightly modified three-step procedure to characterize the solid state partitioning of total trace metals among a number of operationally defined host fractions (Landing and Lewis, 1991). This procedure attempts to resolve three different solid speciation phases, namely: L1) Surface adsorbed phase, i.e., cations adsorbed to carbonates and some Mn-oxyhydroxide phases; L2) Fe-Mn oxide/sulfide carrier phase, i.e., cations co-precipitated with Feoxyhydroxide and some sulfidic phases (FeS), and L3) refractory phases, i.e., metals in alumino-silicates, pyrite and some refractory oxide lattices. In this study, the sum of the first two phases will also be called "reactive phase", and the sum of all three phases will be called total particulate phase. The distinction between L1 and L2 is likely uncertain, since Mn can appear in both phases. The same can be said for $\mathrm{L} 2$ and $\mathrm{L} 3$, as pyritization of sulfidic phases, which is occurring in the upper $10 \mathrm{~cm}$ of Galveston Bay sediments (Morse et al., 1993), can complicate the interpretation of these leach fractions.

Trace metal concentrations in leaches and digestants of particulate matter were measured by graphite furnace atomic absorption spectrometry (GFAAS, Galveston Bay SPM), using a Perkin-Elmer 5100 Atomic Absorption Spectrophotometer (with Zeeman background correction) or by Thermo Elemental PQ ExCell inductively coupled plasma mass spectrometry (ICP-MS, Trinity River SPM), after dilution and with the use of internal standards ${ }^{45} \mathrm{Sc},{ }^{115} \mathrm{In}$ and ${ }^{209} \mathrm{Bi}$ for low, mid and high masses, respectively. The blanks of the three three-step sequential leaching procedure reported in Table 1 were used to correct the results. The Standard Reference Material (SRM) 1646a Estuarine Sediment (National Institute of Standards and Technology), was also subjected to the same three-step leach procedure described above and analyzed similarly to the SPM samples. The percent recovery obtained for the SRM was in agreement with the certified values of $\mathrm{Cu}$ and $\mathrm{Pb}$, and was within $5 \%$ of the values for $\mathrm{Al}, \mathrm{Fe}$ and $\mathrm{V}$ and within $10 \%$ of that certified for $\mathrm{Mn}$. The suggested minimum aliquot (500 mg) necessary to obtain certified values was cut by a factor of 10 to avoid the large dilution factors and associated errors that could lead to deviations from the certified values. The values for Co and Ni were not certified in this reference standard, however. Further analytical details can be found in Wen et al. (1999) and Warnken et al. (2001).

Dissolved $(\leq 0.45 \mu \mathrm{m})$ trace metal concentrations from the Trinity River were determined directly, after sample dilution, using a Thermo Elemental PQ ExCell inductively coupled plasma mass spectrometer (ICP-MS) equipped with a high performance interface (HPI) and running the PlasmaLab software package. The peltier-cooled impact-bead spray chamber and torch originally supplied with the instrument were replaced with a CETAC ultrasonic nebulizer (U-5000AT) and high solids torch (HST-100). The samples were analyzed for $\mathrm{V}, \mathrm{Co}, \mathrm{Ni}, \mathrm{Cu}, \mathrm{Cd}$ and $\mathrm{Pb}$ by ICP-MS after dilution and with the use of internal standards ${ }^{45} \mathrm{Sc},{ }^{115} \mathrm{In}$ and ${ }^{209} \mathrm{Bi}$ for low, mid and high masses, respectively. 

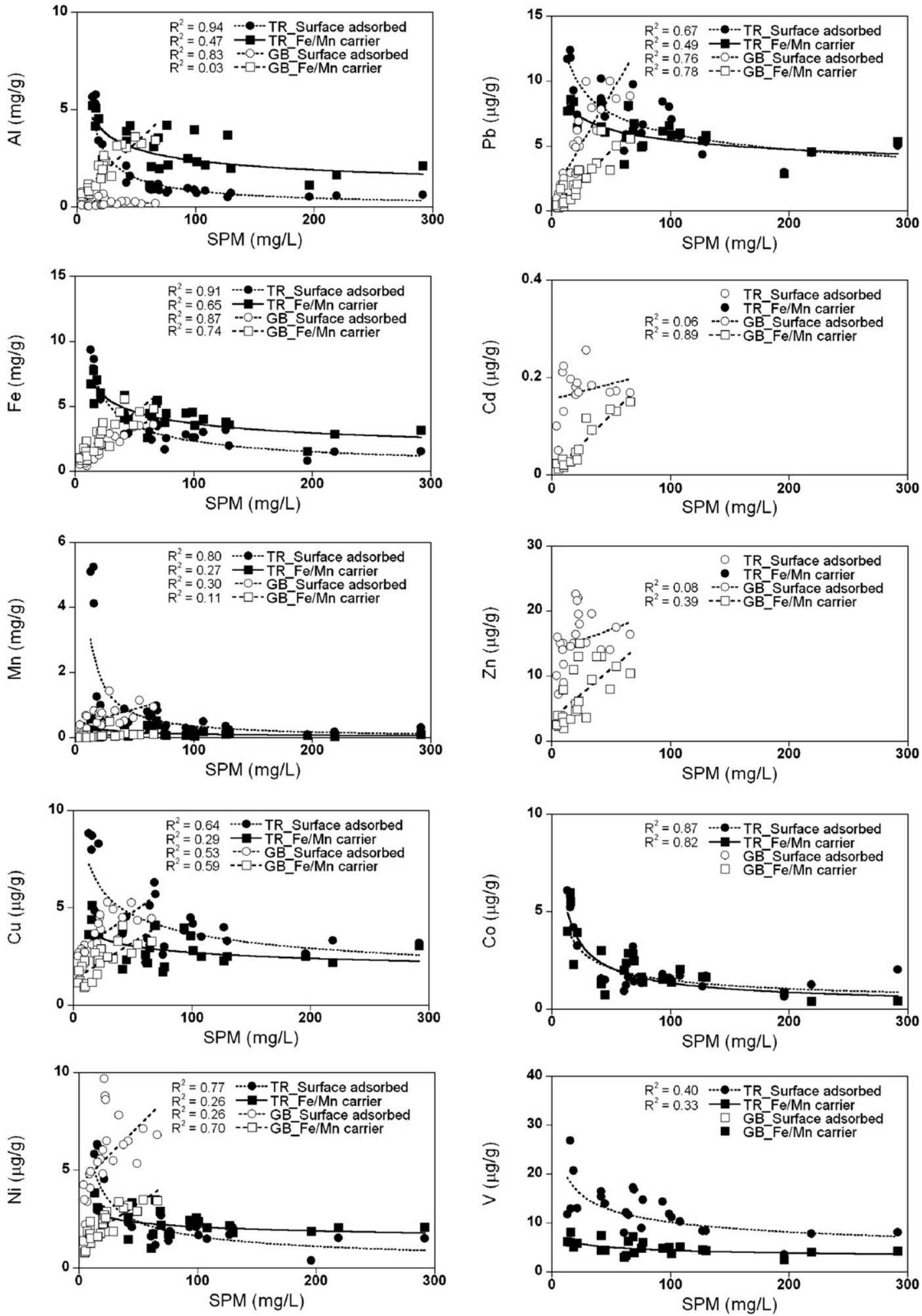

Fig. 3. Relationship between $\mathrm{Al}, \mathrm{Pb}, \mathrm{Fe}, \mathrm{Cd}, \mathrm{Mn}, \mathrm{Zn}, \mathrm{Cu}, \mathrm{Co}, \mathrm{Ni}$, and $\mathrm{V}$ ( $\mathrm{mg} \mathrm{g}^{-1}$ ) measured in the first particle leach, $\mathrm{L} 1$ and the second leach, $\mathrm{L} 2$, vs. suspended particulate matter, SPM (mg L ${ }^{-1}$ ) concentrations for Trinity River (solid symbols) and Galveston Bay particles (open symbols). 

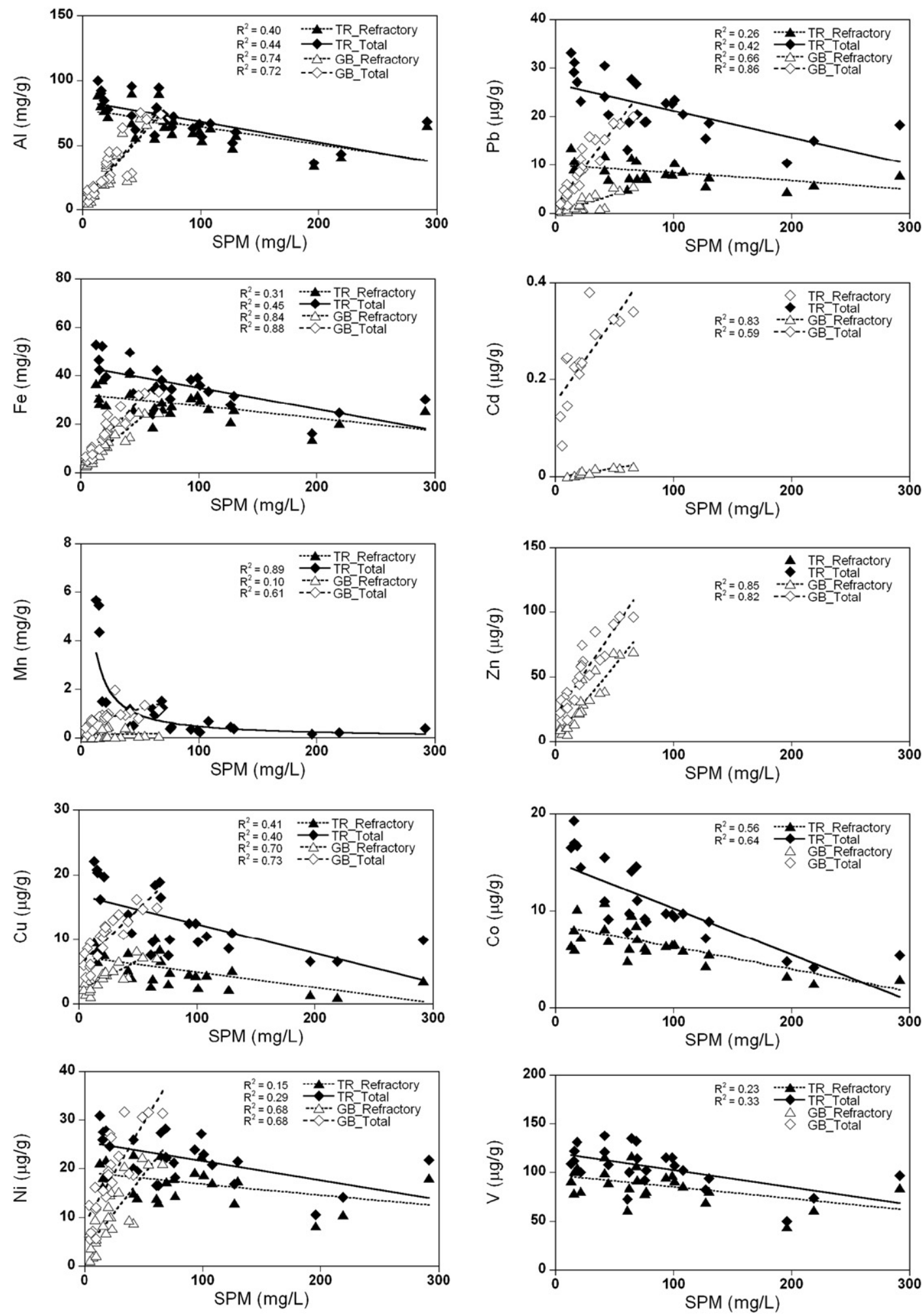

Fig. 4. Relationship between $\mathrm{Al}, \mathrm{Pb}, \mathrm{Fe}, \mathrm{Cd}, \mathrm{Mn}, \mathrm{Zn}, \mathrm{Cu}, \mathrm{Co}, \mathrm{Ni}$, and $\mathrm{V}\left(\mathrm{mg} \mathrm{g}^{-1}\right)$ measured in the third particle leach (L3) and the total leach ( $\mathrm{L} 1+\mathrm{L} 2+\mathrm{L} 3$ ), vs. suspended particulate matter, SPM, concentrations ( $\mathrm{mg} \mathrm{L}^{-1}$ ) for Trinity River (solid symbols) and Galveston Bay particles (open symbols). 


\section{Results and discussion}

\subsection{Particulate trace metals in the Trinity River}

The trace metal concentrations from the Trinity River, as a function of SPM concentrations, are given for each metal in Fig. 3 for the first and second leach, and in Fig. 4 for the third (L3) and total ( $\mathrm{L}_{\mathrm{TOT}}$ ) leach. The decreasing metal content with increasing SPM concentrations, especially apparent for Fe and similar to that observed for POC, indicates a change in the nature of the suspended particles with increasing SPM. Only Mn (78\%), and to a lesser extent $\mathrm{Cu}, \mathrm{Pb}, \mathrm{Co}, \mathrm{Ni}$, and $\mathrm{V}(36,33,30,20$, and $15 \%$, respectively) showed significant levels in the first leach fraction. A strong relationship $\left(R^{2}=0.65-\right.$ 0.93) was observed between Fe and trace metals (except V) in the first particle leach (Table 2, Fig. 3) indicating an association of these metals with reactive Fe rather than $\mathrm{Mn}$, one of the target carrier phases of this leach. In general, it is this first leach fraction that has the largest effect on dissolved trace metal concentrations as it contains the weakly bound metals, which are likely to participate in adsorption/desorption reactions. For instance, one would expect (Buffle, 1990) that at elevated $\mathrm{pH}$ levels ( 8.2, during low discharge rates; Warnken, 2002) metals would be associated to a slightly higher degree with particle surfaces than at lower $\mathrm{pH}(\sim 7.5$, at high discharge rates; Warnken, 2002)

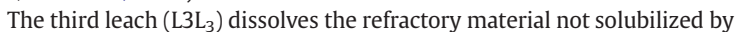
the first two more mild leaches, predominantly the alumino-silicate or clay minerals, as well as some organic matter (Landing and Lewis, 1991). In general, all metals associated with the refractory fraction in the Trinity River samples showed linearly decreasing concentrations with increasing levels of SPM. This observation is the opposite as that for the samples from Galveston Bay, where the refractory metal contents increased with increasing SPM concentrations due to sediment resuspension. The riverine trend is also the opposite of that observed by Shafer et al. (1997) for two contrasting rivers in Wisconsin, where particulate trace metal concentrations increased with increasing discharge. The linear decrease (negative slope) in concentration vs. SPM concentration was most apparent for $\mathrm{Al}, \mathrm{V}$ and $\mathrm{Fe}$, which are three major components of clay minerals, thus likely leaving other Al-silicates and quartz as the main components.

The trace metals $\mathrm{V}, \mathrm{Co}, \mathrm{Ni}, \mathrm{Pb}$, and to a lesser extent $\mathrm{Cu}$ (possibly due to its preference for organic carbon), also showed strong relationships to $\mathrm{Fe}$ and $\mathrm{Al}$ in this $\left(\mathrm{L}_{3} \mathrm{~L}_{3}\right)$ fraction, with $R^{2}$ values ranging from 0.58 for $\mathrm{Cu}$ to 0.77 for $\mathrm{V}$ $(n=24)$ (Table 2). Concentrations of $\mathrm{Al}, \mathrm{V}, \mathrm{Fe}, \mathrm{Co}$, and Ni were highest in this

\section{Table 2}

Regression coefficients for correlations between different metal concentrations $(\mu \mathrm{g} / \mathrm{g})$ in different leachates of Trinity River particles and Fe $(\mathrm{mg} / \mathrm{g})$ in the respective leach

\begin{tabular}{llclll}
\hline Element & Leach & $a$ & $b$ & $r^{2}$ & $p<$ \\
\hline $\mathrm{OC}$ & Total & -47.1 & 2.44 & 0.47 & $\mathbf{0 . 0 0 1}$ \\
$\mathrm{Al}$ & 1 & 0.84 & 0.70 & 0.93 & $\mathbf{0 . 0 0 1}$ \\
$\mathrm{Al}$ & 3 & 10.4 & 1.97 & 0.68 & $\mathbf{0 . 0 0 1}$ \\
$\mathrm{Al}$ & Total & 9.36 & 1.68 & 0.80 & $\mathbf{0 . 0 0 1}$ \\
$\mathrm{V}$ & 1 & 8.18 & 1.23 & 0.03 & - \\
$\mathrm{V}$ & 3 & 18.5 & 2.43 & 0.77 & $\mathbf{0 . 0 0 1}$ \\
$\mathrm{V}$ & Total & 30.9 & 2.03 & 0.72 & $\mathbf{0 . 0 0 1}$ \\
$\mathrm{Mn}$ & 1 & 1.04 & 0.57 & 0.79 & $\mathbf{0 . 0 0 1}$ \\
$\mathrm{Co}$ & 1 & 0.01 & 0.61 & 0.87 & $\mathbf{0 . 0 0 1}$ \\
$\mathrm{Co}$ & 3 & 1.01 & 0.27 & 0.73 & $\mathbf{0 . 0 0 1}$ \\
$\mathrm{Co}$ & Total & -3.3 & 0.40 & 0.78 & $\mathbf{0 . 0 0 1}$ \\
$\mathrm{Ni}$ & 1 & 0.13 & 0.64 & 0.86 & $\mathbf{0 . 0 0 1}$ \\
$\mathrm{Ni}$ & 3 & 2.29 & 0.53 & 0.69 & $\mathbf{0 . 0 0 5}$ \\
$\mathrm{Ni}$ & Total & 3.83 & 0.50 & 0.76 & $\mathbf{0 . 0 0 1}$ \\
$\mathrm{Cu}$ & 1 & 1.98 & 0.73 & 0.73 & $\mathbf{0 . 0 0 1}$ \\
$\mathrm{Cu}$ & 3 & -3.56 & 0.32 & 0.58 & $\mathbf{0 . 0 0 5}$ \\
$\mathrm{Cu}$ & Total & -2.71 & 0.43 & 0.62 & $\mathbf{0 . 0 0 1}$ \\
$\mathrm{Pb}$ & 1 & 4.16 & 0.88 & 0.65 & $\mathbf{0 . 0 0 1}$ \\
$\mathrm{Pb}$ & 3 & -0.16 & 0.31 & 0.71 & $\mathbf{0 . 0 0 1}$ \\
$\mathrm{Pb}$ & Total & 0.49 & 0.62 & 0.88 & $\mathbf{0 . 0 0 1}$ \\
\hline $\mathrm{List}$ & & & & &
\end{tabular}

List of parameters of correlations of $\{\mathrm{Me}\}=a+b\{\mathrm{Fe}\}$; with \{\}$=$ metal concentration; $r^{2}=$ variance $=$ correlation coefficient squared; $p=$ level of significance (with $p<0.01$ in bold); $n=$ number of values $=24$.
Table 3

Comparison of parameters of regressions of $\log \mathrm{Kd}=a-b \log [\mathrm{SPM}]$ for Trinity River particles; SPM = suspended particulate matter $(\mathrm{mg} / \mathrm{L}) ; \mathrm{Kd}=$ particlewater partition coefficient $(\mathrm{L} / \mathrm{kg}) ; r^{2}=$ variance $=$ correlation coefficient squared; $p=$ level of significance (with $p<0.01$ in bold); $n=$ number of values $=24$

\begin{tabular}{|c|c|c|c|c|c|}
\hline Metal & Leach & $a$ & $b$ & $r^{2}$ & $p<$ \\
\hline $\mathrm{Al}$ & 1 & 7.47 & 1.13 & 0.75 & 0.001 \\
\hline $\mathrm{Al}$ & 2 & 6.83 & 0.57 & 0.40 & 0.001 \\
\hline $\mathrm{Al}$ & 3 & 7.97 & 0.45 & 0.33 & 0.005 \\
\hline $\mathrm{Al}$ & Total & 8,96 & 0.48 & 0.36 & 0.002 \\
\hline V & 1 & 4.14 & 0.20 & 0.18 & 0.05 \\
\hline V & 2 & 3.51 & 0.08 & 0.066 & 0.20 \\
\hline V & 3 & 4.63 & 0.001 & $1 \times 10^{-5}$ & 1 \\
\hline V & Total & 4.77 & 0.033 & 0.01 & 0.7 \\
\hline Mn & 1 & 8.50 & 1.78 & 0.57 & 0.001 \\
\hline Mn & 2 & 6.93 & 1.24 & 0.38 & 0.01 \\
\hline $\mathrm{Fe}$ & 1 & 7.90 & 1.18 & 0.69 & 0.001 \\
\hline $\mathrm{Fe}$ & 2 & 7.48 & 0.86 & 0.55 & 0.001 \\
\hline $\mathrm{Fe}$ & 3 & 8.00 & 0.71 & 0.52 & 0.001 \\
\hline $\mathrm{Fe}$ & Total & 8.24 & 0.78 & 0.56 & 0.001 \\
\hline Co & 1 & 5.31 & 0.69 & 0.62 & 0.001 \\
\hline Co & 2 & 4.86 & 0.45 & 0.38 & 0.002 \\
\hline Co & 3 & 5.00 & 0.22 & 0.19 & 0.05 \\
\hline Co & Total & 5.49 & 0.38 & 0.51 & 0.001 \\
\hline $\mathrm{Ni}$ & 1 & 4.17 & 0.65 & 0.60 & 0.001 \\
\hline $\mathrm{Ni}$ & 2 & 3.42 & 0.21 & 0.30 & 0.005 \\
\hline $\mathrm{Ni}$ & 3 & 4.70 & 0.20 & 0.30 & 0.005 \\
\hline $\mathrm{Ni}$ & Total & 4.48 & 0.26 & 0.47 & 0.001 \\
\hline $\mathrm{Cu}$ & 1 & 4.65 & 0.59 & 0.56 & 0.001 \\
\hline $\mathrm{Cu}$ & 2 & 4.20 & 0.44 & 0.45 & 0.001 \\
\hline $\mathrm{Cu}$ & 3 & 5.01 & 0.78 & 0.56 & 0.001 \\
\hline $\mathrm{Cu}$ & Total & 5.13 & 0.61 & 0.59 & 0.001 \\
\hline $\mathrm{Pb}$ & 1 & 6.92 & 0.81 & 0.67 & 0.001 \\
\hline $\mathrm{Pb}$ & 2 & 6.62 & 0.68 & 0.62 & 0.001 \\
\hline $\mathrm{Pb}$ & 3 & 6.73 & 0.66 & 0.59 & 0.001 \\
\hline $\mathrm{Pb}$ & Total & 7.24 & 0.71 & 0.64 & 0.001 \\
\hline
\end{tabular}

$\left(\mathrm{L}_{3} \mathrm{~L}_{3}\right)$ leach fraction and on average accounted for $94,83,78,61$ and $78 \%$ of the total particulate fraction, respectively. The high fraction of $\mathrm{Al}$ and $\mathrm{V}$ in $\mathrm{L} 3$ indicates strong association with Al-silicate phases (Shiller and Mao, 2000). Copper and $\mathrm{Pb}$ showed similar concentrations in L1 and L3, while $\mathrm{Mn}$ concentrations were highest in the L1, which targets Mn-oxyhydroxide minerals (Figs. 3 and 4). Manganese showed very low concentrations in L2 (Fig. 3) and undeterminable concentrations in L3 (Fig. 4). This is in agreement with results from similar leach experiments conducted on suspended materials collected from Trinity Bay waters and Trinity Bay sediments (Warnken et al., 2001). In these sediments, Al contents of approximately $80 \mathrm{mg} \mathrm{g}^{-1}$ and Fe contents of approximately $30 \mathrm{mg} \mathrm{g}^{-1}$ were measured, similar to the total concentrations of these metals in the Trinity River at high SPM concentrations (Fig. 4), further indicating this suspended material undergoes little alteration before burial in the sediments.

The strong correlation with Fe and the decreasing metal content with increasing SPM concentrations measured in the third particle leach clearly indicates dilution of clay minerals by particles with reduced trace metal content (e.g., quartz). As mentioned earlier, SPM was linearly correlated with the Trinity River discharge (Warnken and Santschi, in press), and Al concentrations in the third leach ( ${\mathrm{L} 3 \mathrm{~L}_{3}}_{3}$ ) decreased with increasing SPM concentrations (Fig. 4). The presence of $\mathrm{Al}$ at high SPM in the third leach indicates a clay component is still present, although reduced from that present at low SPM levels. The particles at high SPM concentrations had a reduced OC content, as it generally shows a nonlinear decline with increasing SPM concentrations, leveling off at $1-2 \%$ OC at high SPM concentrations (Warnken and Santschi, 2004). Quartz and silicate minerals, with reduced surface area to volume ratios and weak surface sorption sites, would become suspended at increasingly higher levels of discharge and would dilute the clay mineral signature measured at low discharge. The strong positive correlation between trace metals and $\mathrm{Fe}$ in the respective fractions, especially in the L1 and L3 fractions (Table 2) indicates that these metals are associated with an Fe-containing alumino-silicate mineral fraction, a fraction that can still undergo, albeit slow, diagenesis after burial in sediments (Michalopoulos and Aller, 2004). 
The partitioning of trace metals between the dissolved (filter passing) and particulate (filter retained) fractions, as a $\mathrm{Kd}$, is one of the most widely used means of expressing the distribution, transport, behavior, and fate of a particular metal in aquatic environments (Benoit et al., 1994; Benoit and Rozan, 1999). A decrease in the partition coefficient (Kd) of a metal between the particulate and dissolved fraction with increasing concentrations of SPM, termed the "particle concentration effect" (O'Connor and Connolly, 1980; Honeyman and Santschi, 1989; Santschi et al., 1997; Wen et al., 1997b), should not occur if this partitioning would be ideal; however, it is observed in our data (Table 3). As can be seen from the slope $(b)$ values, they are all negative and significant. This inverse dependency of Kd on SPM in Trinity River particulate metals can arise from a number of factors, including the inclusion of colloidally bound trace metals in the dissolved fraction (Benoit et al., 1994; Benoit and Rozan, 1999, and references therein) that can lead to "colloidal pumping" (Honeyman and Santschi, 1989; Wen et al., 1997b), or the dilution of suspended particles with coarser material (e.g., silicate minerals) that sorbs trace metals to a lesser extent. It is likely that both factors operate in Galveston Bay to some degree.

\subsection{Particulate trace metals in Galveston Bay}

The estuarine distributions of selected metals ( $\mathrm{Al}, \mathrm{Fe}, \mathrm{Mn}, \mathrm{Cd}, \mathrm{Cu}, \mathrm{Ni}, \mathrm{Pb}, \mathrm{Zn}$ ) in the water during July 1993 and 1995 transects are shown in Fig. 6. The estuarine distribution patterns of these metals are broadly similar to those of SPM and/or POC (Fig. 5). While water discharge rates were similar during both sampling times (i.e., $100 \mathrm{~m}^{3} / \mathrm{s}$ ), the Trinity River discharge rate in 1993 was considerably higher $\left(600 \mathrm{~m}^{3} / \mathrm{s}\right) 1-2$ weeks before sampling, while in 1995 , it was relatively constant the weeks before. Thus, the estuarine hydraulic residence time, which averages 40-90 days (Armstrong, 1982), would have been a lot shorter in 1993 than in 1995, which would have allowed sediment-water fluxes to build up to higher concentrations in Upper Galveston Bay in 1995 than in 1993. Highly concave estuarine distributions were indeed observed in 1995 for POC and SPM (Fig. 5), as well as for all particulate trace metals (Fig. 6). In addition, in order to fully understand the differences between the two years, sediment resuspension due to wind and wave action would have to be considered as well.

When the metal concentration in particles (rather than the water) is plotted as a function of salinity for the two time periods, significant differences were observed (Fig. 7a,b). For particles collected during 1993, the concentrations of metals in particles correlated linearly with salinity. For all elements, a decreasing trend of their concentrations in all phases as a function of salinity was observed, however, with slopes that show significant differences between years and between leach fractions. For example, two distinct estuarine mixing regions are apparent for the July 1995 sampling expedition (Fig. 7a,b), a more dynamic upper bay region with more intensive sediment resuspension and/or faster sedimentation (steeper slope of SPM vs. salinity plot), and a less dynamic lower bay region dominated by simple linear mixing patterns, with more limited sediment resuspension, and slower sedimentation. Distinctly different mixing patterns were also observed for dissolved constituents for the two summers, with more linear mixing in July 1993, and a more convex mixing pattern in July 1995 (Wen et al., 1997a, 1999).

For Mn, the majority of it was present in the surface adsorbed fraction (L1), similar to the samples from the Trinity River. For $\mathrm{Pb}$, the majority was in L1 for samples from Galveston Bay, while they were about equally distributed between L1 and the refractory phase (L3) for Trinity River samples. The carrier-phase metals Al and Fe from Galveston Bay, on the other hand, were found predominantly in L3 (Fig. 7a), similar to these metals in the Trinity River samples. For the nutrient-type elements $\mathrm{Cu}, \mathrm{Zn}$ and $\mathrm{Ni}$, relatively large proportions were found in both L1 and L3 (Fig. 7b). Significant amounts (i.e., $\geq 10 \%$ ) of all metals, except $\mathrm{Al}$, were also associated with the Fe/Mn carrier phase (L2). A number of the trace metals (e.g., $\mathrm{Cu}, \mathrm{Pb}$ ) had similar solid speciation patterns when comparing the two sampling periods. Ni was evenly distributed between L1 and L3, with contribution of 40\% for both fractions. For Zn, the largest fraction in 1993 was in L1, and in 1995, it was in L3, with changing slopes for the concentration of L1 fraction vs. salinity. But for the carrier carrier-phase metal Mn, distinct differences were observed. Identical amounts were present in both L1 and L3 during July 1993, but during July 1995, major amounts were found in the L1 only (over 90\%). For the carrier carrier-phase metals Fe and Al, L3 was the dominant fraction, but to a different degree during the two sampling periods. These results, along with the non-linear decrease of their concentrations from the Trinity River to the Gulf of Mexico during the July 1995 transect (Fig. 4), could have been produced by a combination of processes, including pyritization of trace metals in sediments (e.g., Cu; Morse et al., 1993), followed by oxidation during bottom sediment resuspension, sediment remobilization followed by benthic fluxes and re-adsorption of dissolved species or desorption of particle-bound species. During July 1993, however, the situation appeared simpler, with the different particulate phases of the trace metals decreasing almost linearly from the Trinity River to the Gulf of Mexico, and the particulate trace metal concentrations decreasing rapidly and in a concave fashion with salinity indicating removal.

The relative $\mathrm{L} 1$ to $\mathrm{L} 3$ fractions for $\mathrm{Al}$, Fe and Mn during the two sampling periods remained relatively constant throughout the bay. For $\mathrm{Cd}, \mathrm{Zn}$ and $\mathrm{Ni}$, the percentage in the surface adsorbed phase either increased with salinity in upper Galveton Bay samples in 1995, or stayed constant, while their concentrations in the refractory phase decreased with salinity (Fig. 7b). For $\mathrm{Ni}$ and $\mathrm{Zn}$, the correlations of their concentrations in different solid phases with salinity were reversed during different times, possibly due to differences in OC and Fe cycling, which showed a steady decrease in DOC and POC concentrations throughout the bay in 1993, and a mid-bay maximum for POC and DOC concentrations in 1995, likely indicating more intense sediment-water interactions during the 1995 sampling expedition (Guo and Santschi, 1997a; Wen et al., 1999).

Most importantly, metal concentrations in suspended particles decrease with increasing SPM concentration from the Trinity River (Figs. 3, 4), regardless
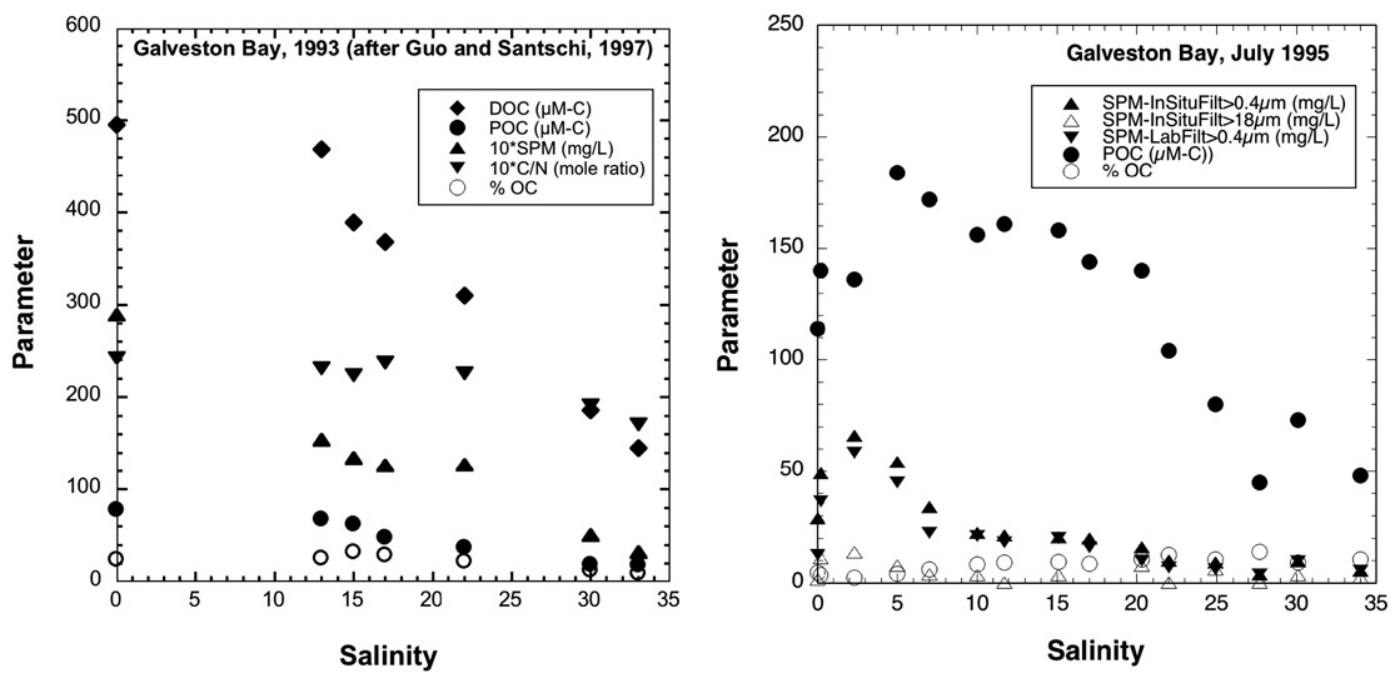

Fig. 5. Concentrations of SPM, POC, DOC, and C/N atomic ratios for a) 1993 (after Guo and Santschi, 1997a,b) and b) 1995 sampling expeditions. 

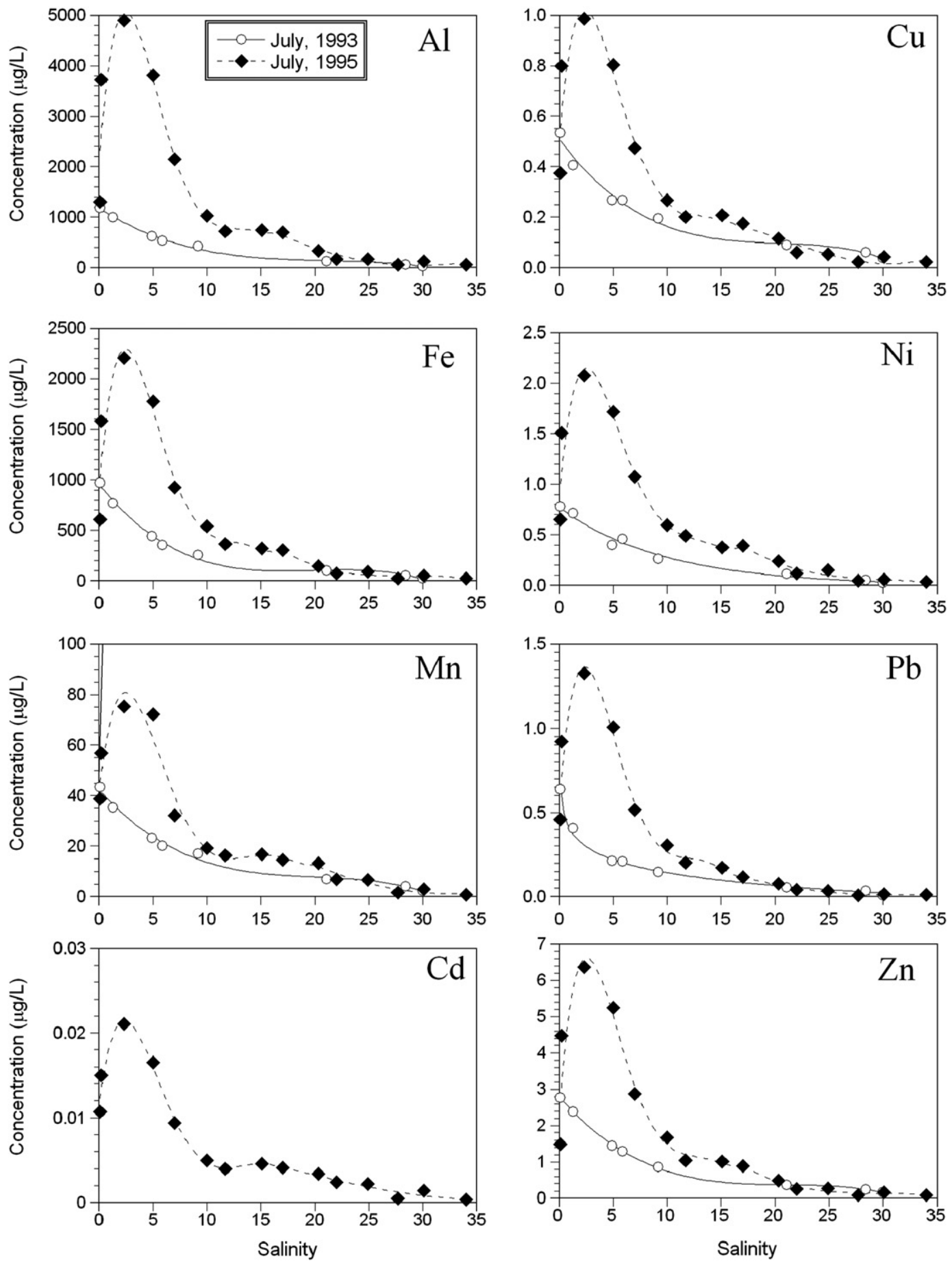

Fig. 6. Estuarine distributions of particulate trace metals concentrations ( $\mu \mathrm{g} / \mathrm{L})$ during July 1993 and July 1995.

of leach fraction or metal, but generally increase with increasing SPM concentration in Galveston Bay (Figs. 3,4). This strongly suggests different processes regulating metal concentrations on river vs. bay particles. While in the Trinity River, hydrodynamic sorting might be responsible for the negative relationship with SPM concentration, it might be the combination of sediment resuspension, turbidity enhancements due to salt-induced coagulation reactions, and enhanced primary productivity that is capable of changing the originally negative correlation to a positive one in Galveston Bay.
3.3. Elemental ratios to $\mathrm{Al}, \mathrm{Fe}$, and $\mathrm{OC}$ as indicators for suspended particle sources and processes in Galveston Bay

Elemental ratios in total suspended matter have been used to study transport processes, and to deduce sources of particles in river, estuarine and ocean water. Aluminum is a major component of suspended matter; it is believed to be almost entirely associated with Al-silicates, mainly clay minerals (Duinker, 1981; Windom et al., 1988, 1989). The element:aluminum ratio (M/Al) 
can be used to study the relative importance of pollution sources (Windom et al., 1988, 1989; Summers et al., 1996), and of aluminum-silicates relative to other minerals and organic matter as surfaces for metal sorption (Duinker and
Nolting, 1978). Because correlations between $\mathrm{Al}$ and Fe and/or OC (Fig. 8) are highly significant $(p<0.001)$ for Trinity River particles, both Fe and Al can act as a proxy for the organically associated $\mathrm{Al}$ and $\mathrm{Fe}$ Fe-oxyhydroxides and/or clay
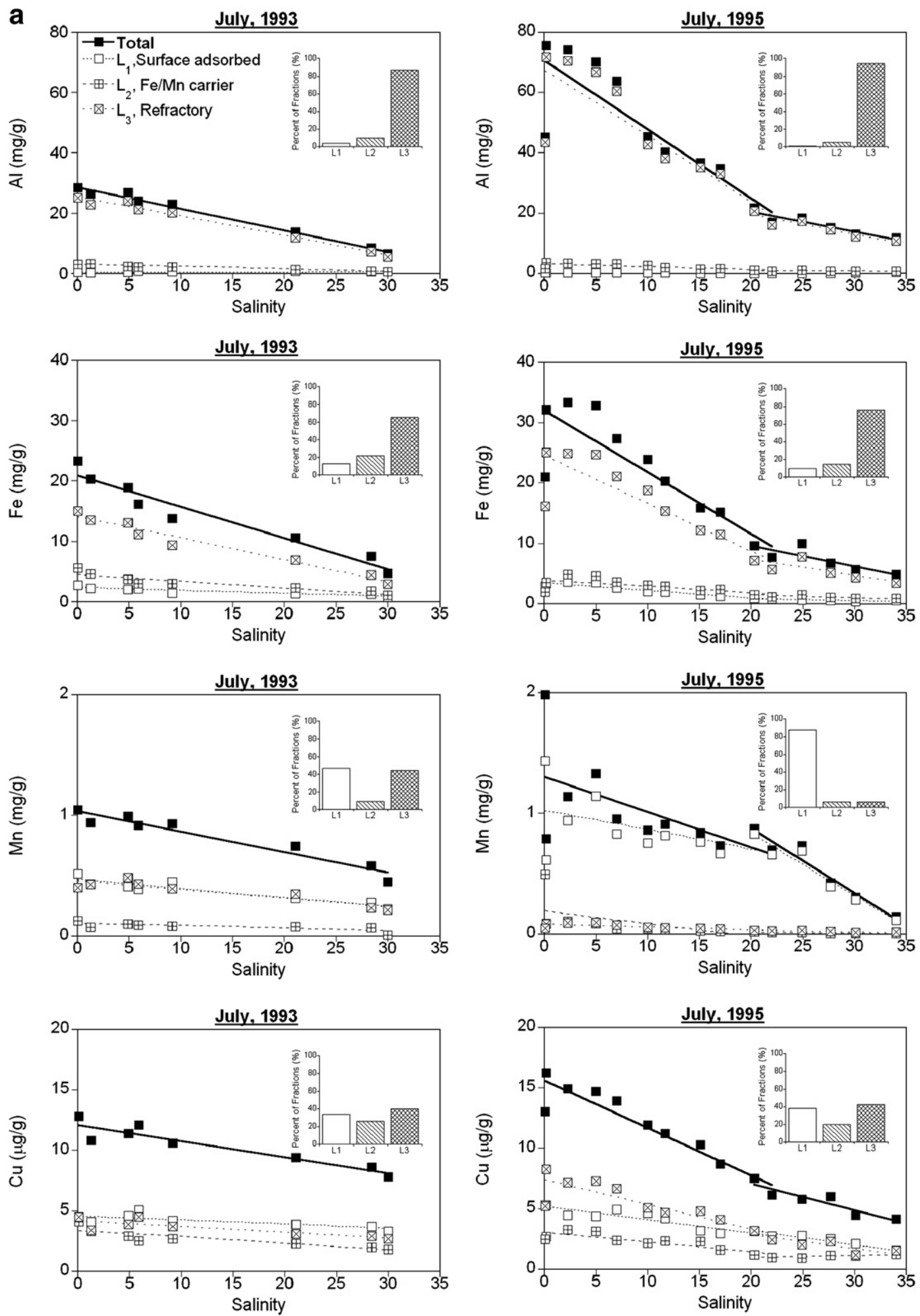

Fig. 7. Estuarine distribution of trace metal concentrations in suspended particles, as a function of salinity during different transects, as well as average distribution of metals in different host fractions of suspended particles; a) $\mathrm{Al}, \mathrm{Fe}, \mathrm{Mn}, \mathrm{Cu}$; b) $\mathrm{Ni}, \mathrm{Pb}, \mathrm{Zn}, \mathrm{Cd}$. 

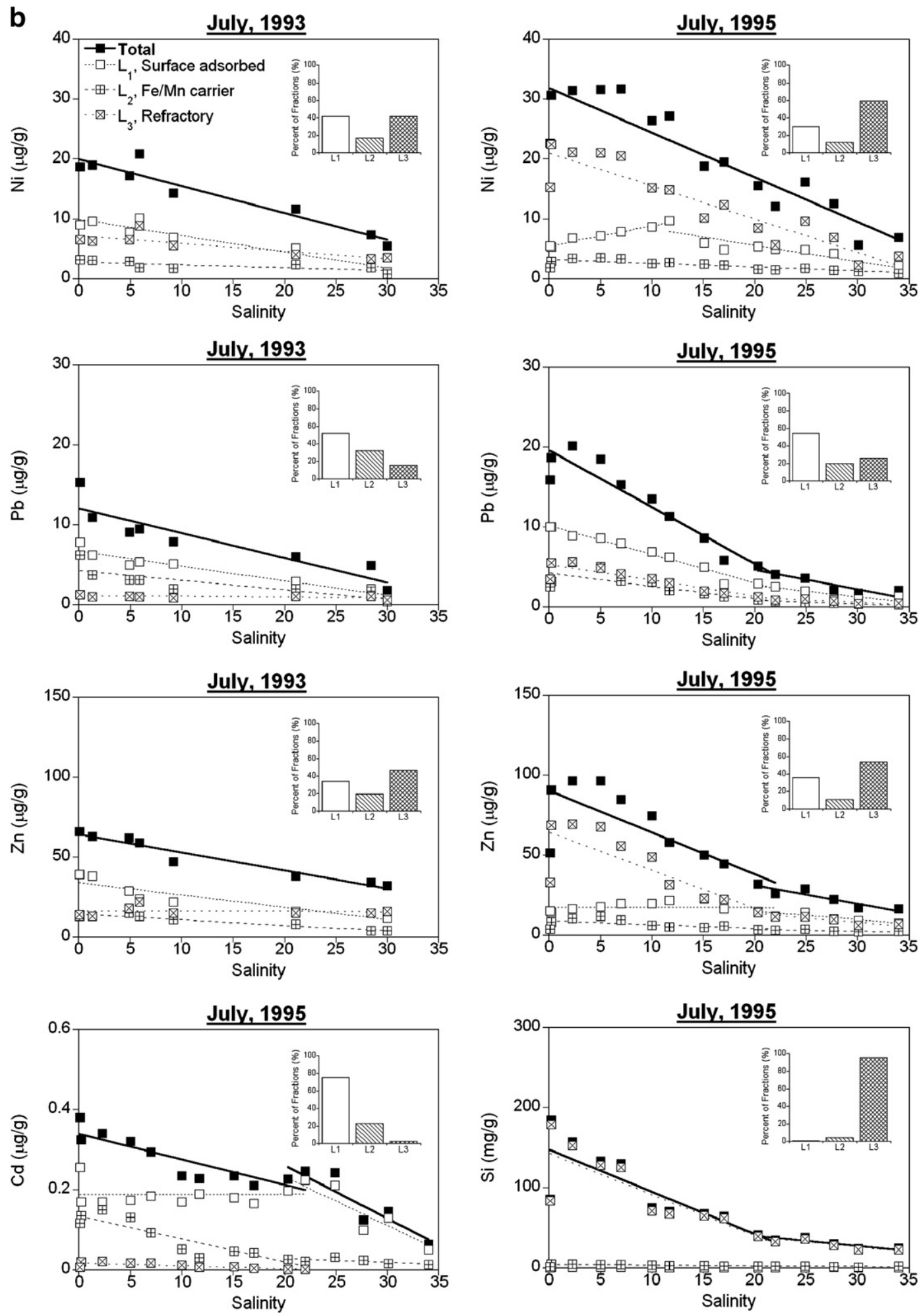

Fig. 7 (continued).

minerals (i.e., the association of iron with humics and clays). Even though correlations between Fe and $\mathrm{OC}$ in Trinity River particles are slightly less significant, $p$ values are still $<0.001$ (Table 2). However, for Galveston Bay particles, this close correlation does not hold up for $\mathrm{OC}$, as OC/Fe or OC/Al ratios are not constant, and trace metal to OC ratios, at times (e.g., in 1995) decrease with increasing OC concentration. As the mineral matter (clays, etc.) is removed 
by sedimentation and diagenesis, it is replaced by OC. Furthermore, NOM is likely affected by differences in OC sources, diagenesis and/or cycling. When allochthonic $\mathrm{OC}$ is replaced by autochthonic $\mathrm{OC}$ within the estuary, trace metal partitioning to NOM can be affected. As an example that OC sources changed in Galveston Bay during that time, we have records of $\mathrm{C} / \mathrm{N}$ ratios in colloidal organic matter $\geq 1 \mathrm{kDa}\left(\mathrm{COM}_{1}\right.$, amounting to $50-60 \%$ of DOC). C/N ratios in $\mathrm{COM}_{1}$ decreased linearly from 26 to 18 (when salinity increased) in 1993, demonstrating the terrestrial organic matter influence over all of Galveston Bay, while in 1995 , they stayed constant at 20 between salinity of 0 to 20 , and were 10 between salinity of 25 and 35 , demonstrating the stronger influence of in-situ produced aquagenic organic matter in 1995, especially in the lower reaches of Galveston Bay (Guo and Santschi, 1997a,b).

Plots of M/Al ratios vs. SPM concentrations during different transects are shown in Fig. 9. Relatively constant ratios at high SPM concentrations (upper bay) were observed, as expected for a riverine source (July, 1993) or a region with high sediment resuspension (July, 1995), even though $\mathrm{Fe} / \mathrm{Al}$ ratios decreased by about $20 \%$ to the mid-bay region, indicating removal of Fe from the particulate phase. This decrease in $\mathrm{Fe} / \mathrm{Al}$ ratios is consistent with a coupling of sediment resuspension by wind and wave action, with $\mathrm{Fe}$ diagenesis in the sediments. Fe-oxide reduction in the sediment due to $\mathrm{OC}$ mineralization would lead to a decrease of the particulate $\mathrm{Fe} / \mathrm{Al}$ ratio in the sediment prior to resuspension. This explanation is supported by the dissolved Fe depth-profiles reported in Warnken et al. (2001) that indicate Fe-oxide reduction is occurring in the sediments of Galveston Bay.

At lower SPM concentrations, metal to $\mathrm{Al}$ ratios increase with decreasing SPM concentrations, likely due to particle fractionation processes, such as differential sedimentation, resuspension and flocculation, allowing fine suspended matter to become enriched in secondary carrier phases such as organic matter or Fe/Mn Mn-oxyhydroxides. Distinctive differences were observed between the two transects, with higher metal/Al ratios during July 1993, when resuspended bottom sediments with lower metal and lower Al contents were abundant. The Si/Al ratio was $2.0 \pm 0.2$ in 1995 , which was lower than that for world-average river suspended sediment $(\sim 3.0$; Salomons and Forstner, 1984; Li, 2000). During July 1995, the metal/Al ratios in particles from the upper Trinity Bay (salinity of 2.5) where a turbidity maximum was observed at that time, were similar to those of surface sediments from Galveston Bay described in other studies (Jiann, 1993; Morse et al., 1993). This indicates that resuspended bottom sediments were the cause for the high concentration of suspended particles found in this area.

The increase of the M/Al ratios with decreasing SPM concentrations was different in 1993 and 1995. Fe/Mn Mn-oxyhydroxide enrichment would likely have caused an increase of the Fe/Al ratio in the SPM, which, however, is not in agreement with what was observed in 1995 in the lower bay (10-20 mg/LSPM),

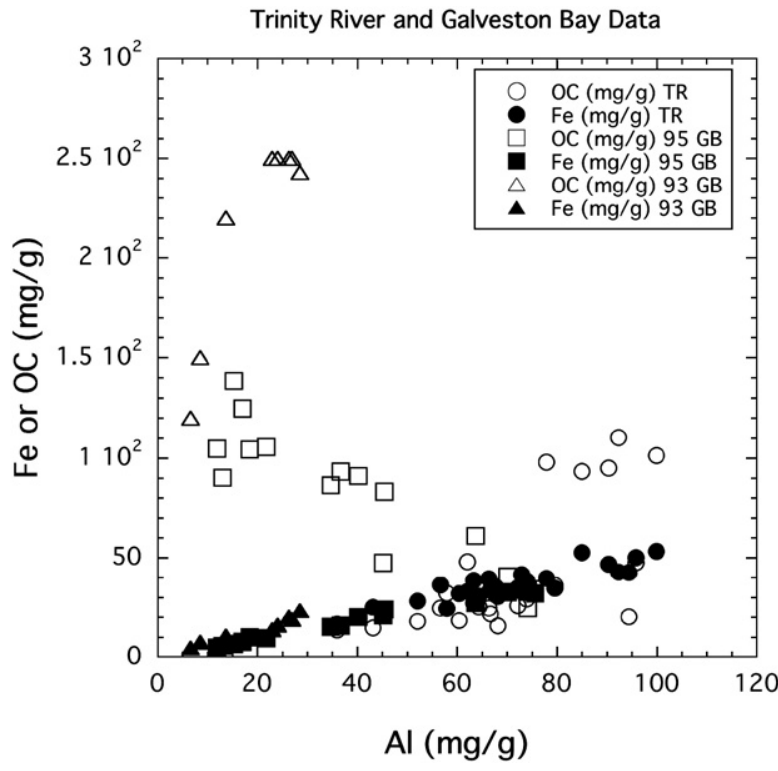

Fig. 8. Comparison of Fe or OC content vs. Al content (mg/g) for particles from the Trinity River and Galveston Bay.

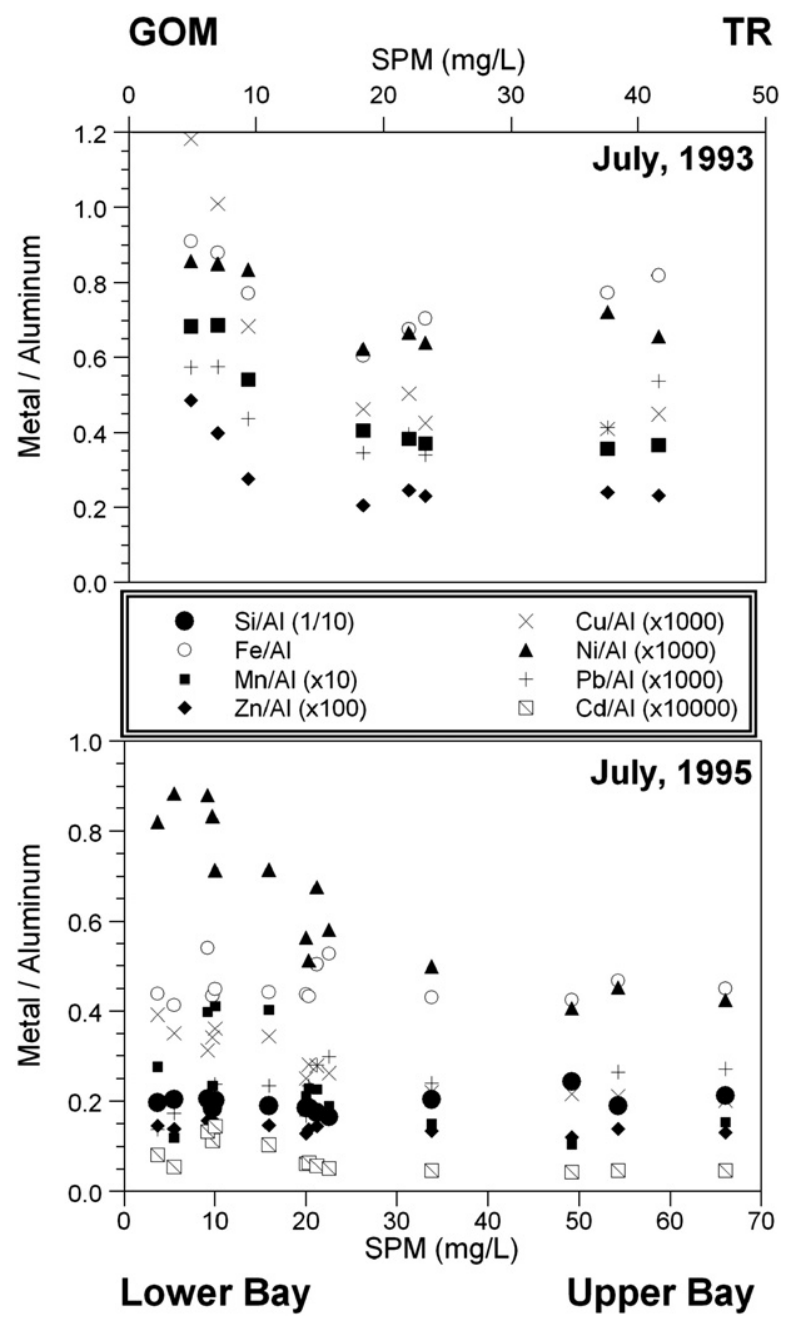

Fig. 9. Element:aluminum ratios $(\mathrm{M} / \mathrm{Al})$ as a function of SPM concentrations during different estuarine transects. GOM = Gulf of Mexico; TR = Trinity River.

when most values of $\mathrm{Fe} / \mathrm{Al}$ ratios were around 0.45 (i.e., soil signature). The increase of nutrient-type metals (Ni, Cu) to Fe ratios in the lower bay in 1995 suggests that association of trace metals with autochthonous organic matter might be the main controlling parameter of particulate trace metals behavior in the lower bay for 1995. Similar processes were proposed for other estuaries (e.g., Audry et al., 2007).

Strong correlations between Fe and various major and trace metals ( $\mathrm{Al}, \mathrm{Cu}$, $\mathrm{Pb}, \mathrm{Zn}, \mathrm{Ni}$ ) in suspended particles from the Trinity River (Fig. 10) are in agreement with the view that incorporation of these elements into particles is, to a significant extent, related to the formation of Fe Fe-oxyhydroxide/sulfide phases. Correlations of metal to Fe ratios with the Fe content of particles from Galveston Bay were found to be significant and positive for particle-reactive elements such as $\mathrm{Pb}$ (Fig. 11a), but negative for nutrient-type elements such as $\mathrm{Cu}, \mathrm{Ni}$, and $\mathrm{Cd}$ $(p<0.01$; Fig. 11b), while suspended particles from the Trinity River did not exhibit any such correlations at all and only varied within a very limited range. As a matter of fact, $\mathrm{Pb} / \mathrm{Fe}$ and $\mathrm{Cu} / \mathrm{Fe}$ ratios in Trinity River particles, when plotted as a function of increasing Fe concentrations, are somewhat lower than those in world-average soils (Fig. 11a,b; Table 5). However, $\mathrm{Pb} / \mathrm{OC}$ and $\mathrm{Cu} / \mathrm{OC}$ ratios, when plotted as a function of increasing $O C$ concentrations, show similar trends to those of Fe/OC ratios (Fig. 11e), with relatively constant and low values only for Galveston Bay particles from 1993, when the bay contained more allochthonous OC. On the other hand, $\mathrm{Pb} / \mathrm{OC}, \mathrm{Cu} / \mathrm{OC}$ and $\mathrm{Fe} / \mathrm{OC}$ ratios in Galveston Bay particles from 1995 vary inversely with OC concentrations, similar to those from the Trinity River (Fig. 11c,d), and reach asymptotically those values of the Galveston Bay 

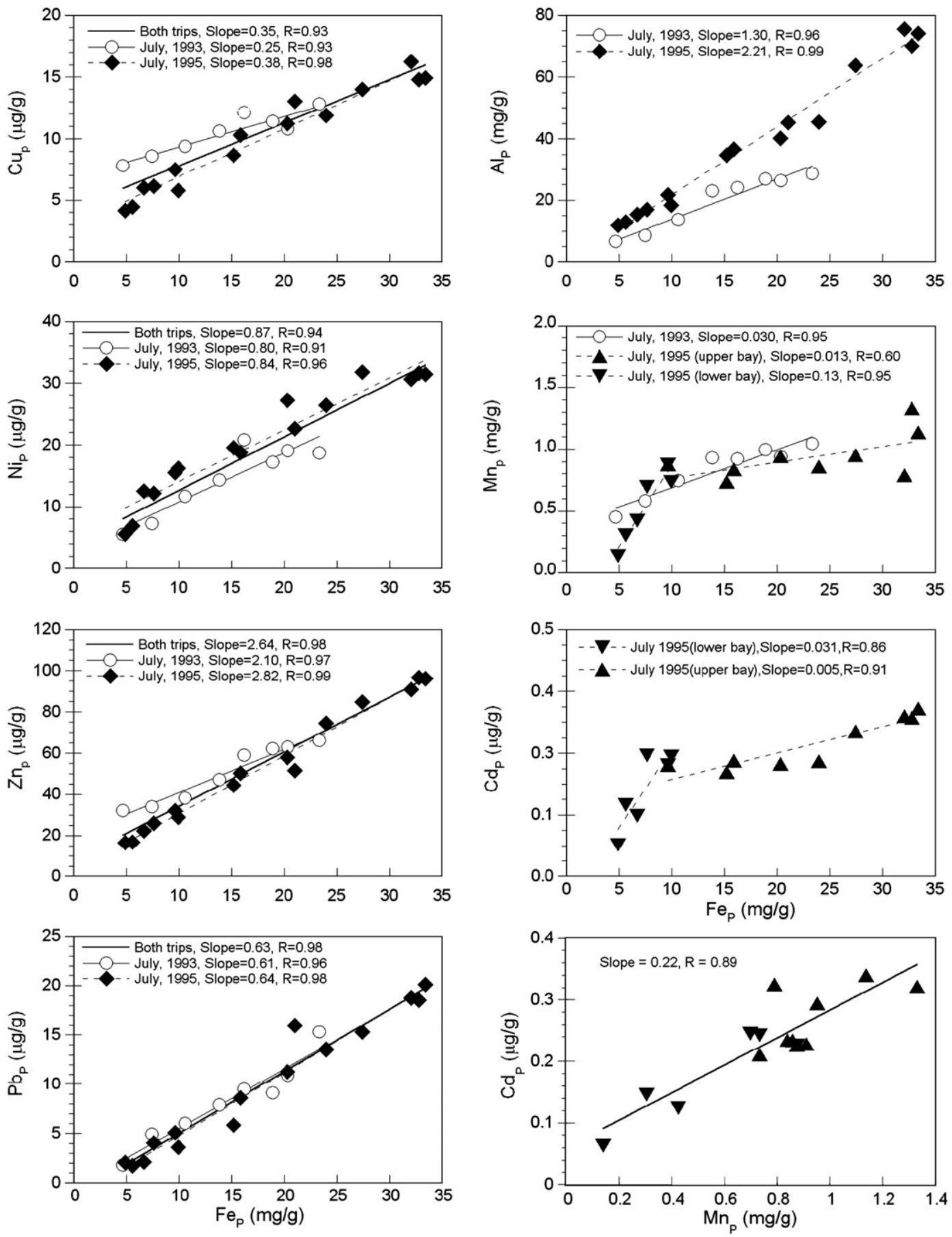

Fig. 10. Particulate metal concentrations vs. particulate Fe concentration in suspended particles ( $\mu \mathrm{g} / \mathrm{g}$ ), as well as correlations between particulate Cd and Mn concentrations.

particles from 1993. These differences in metal/OC and metal/Fe ratios between Trinity River and Galveston Bay particles, together with the close similarity of the different trend lines of $\mathrm{Pb} / \mathrm{OC}$ and $\mathrm{Cu} / \mathrm{OC}$ ratios to those $\mathrm{Fe} / \mathrm{OC}$ ratios for the different particles, are a strong indication for the controls that diagenesis and different sources of the OC and Fe carrier phases impose on the metal content of suspended particles.

Metal to Al ratios (Table 4) indicate that most metals in the Trinity River have a signature similar to that of drainage basin soil particles, while $\mathrm{Pb}, \mathrm{Ni}$, and $\mathrm{Mn}$ in Galveston Bay waters are enriched by a factor of 2-3. Trace metal/Al or
metal/Fe ratios are not elevated when compared to published ratios for uncontaminated environments in the Gulf of Mexico or other relatively pristine environments (e.g., Windom et al., 1988, 1989; Summers et al., 1996), with the possible exception of Cd and $\mathrm{Mn}$ (Tables 4 and 5). Cd appears elevated by about a factor of 3, and Mn by about a factor of 2 over soil ratios to Al or Fe. However, the strong similarity of the solid speciation of Cd with that of $\mathrm{Mn}$ (i.e., L1 > L2 $\gg$ L3) for Galveston Bay and Trinity River particles during both years suggest another reason: involvement with the natural Mn cycle. Even though $\mathrm{Ni} / \mathrm{Al}$ might be elevated over soil ratios by a factor of 2 (Table 4), Ni/Fe ratios are not (Table 5). 
a

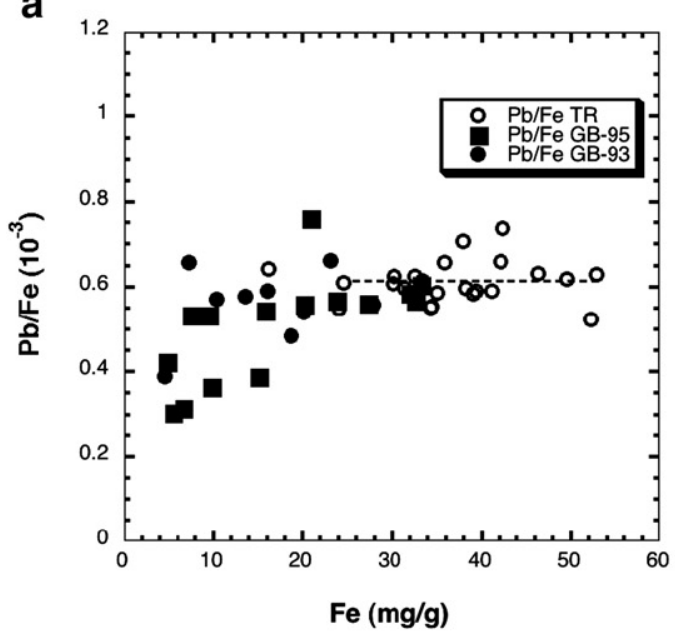

C

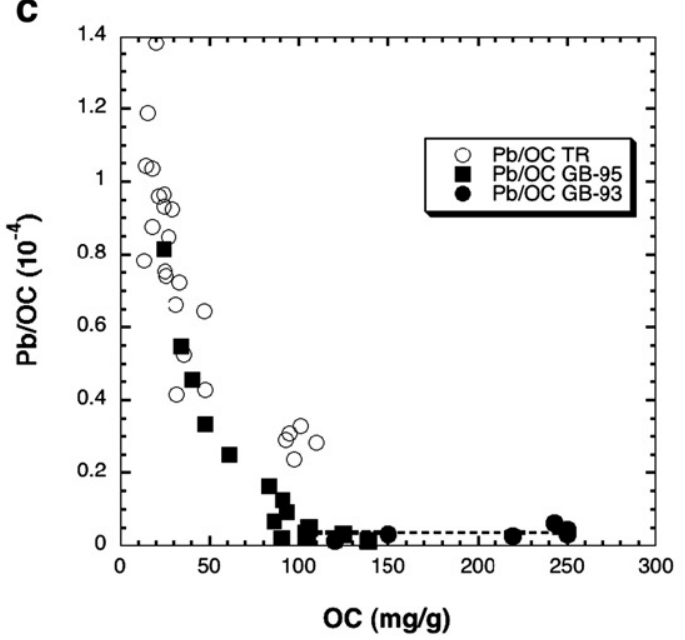

e

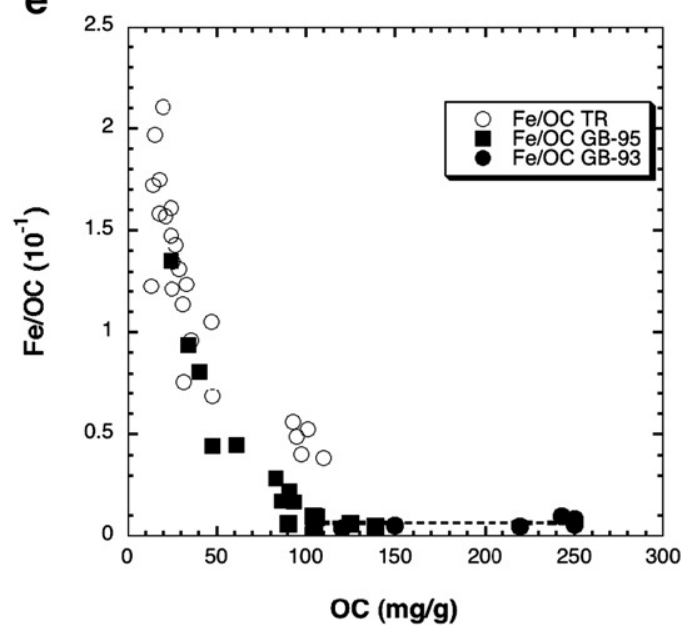

b

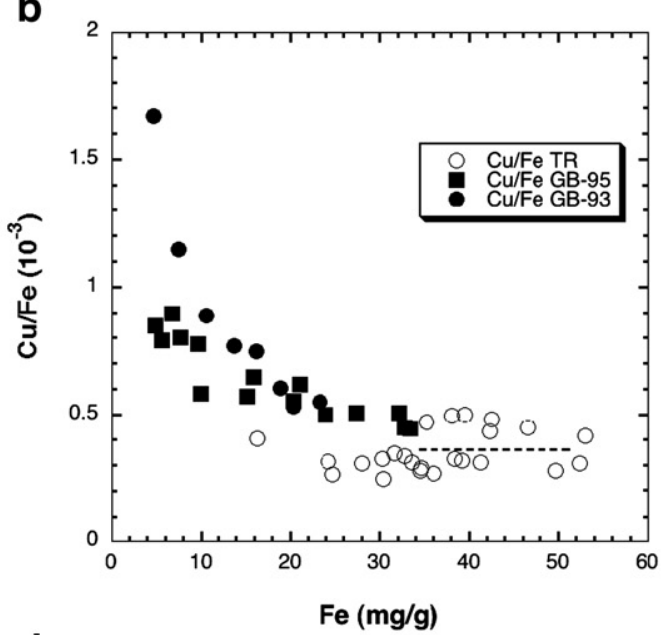

d

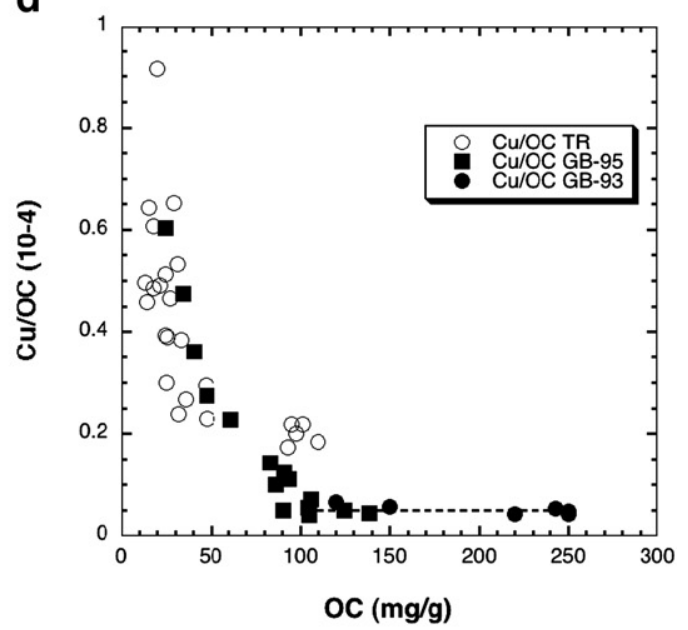

Fig. 11. Comparison between relationships for $\mathrm{Pb}$ (or $\mathrm{Cu}$ ) to $\mathrm{Fe}$ (or $\mathrm{OC}$ ) ratios vs. Fe (or OC) content, as well as Fe/OC ratios vs. OC content, of suspended particulate matter in Galveston Bay and Trinity River. Dashed lines indicate asymptotic values.

Thus, the similarity with soil ratios for $\mathrm{Co}, \mathrm{Cu}, \mathrm{Pb}$ and $\mathrm{Zn}$ strongly indicate that these elements are not elevated by pollution sources. The likely reason for this is the efficient removal of trace metals downstream from pollution sources, e.g., for the sources from the Dallas Metroplex behind the dams along the Trinity
River, the biggest one in Lake Livingston, and from the Houston Metroplex within the Houston Ship Channel.

Trace metals can be enriched, relative to $\mathrm{Al}$, for different reasons, including enrichment in Fe/Mn oxide (or sulfide) and organic matter carrier 


\section{Table 4}

Comparison of X/Al ratios in Trinity River drainage basin soils and Trinity River and Galveston Bay suspended particles with average soil ratios

\begin{tabular}{llllll}
\hline $\begin{array}{l}\text { Element } \\
\mathrm{X}\end{array}$ & $\begin{array}{l}\text { Soil } \\
\text { average } \\
(\text { Li, 2000) }\end{array}$ & $\begin{array}{l}\text { Lake Waco } \\
\text { (Abraham, } \\
1998)\end{array}$ & $\begin{array}{l}\text { Lake } \\
\text { Livingston } \\
\text { (Van Metre } \\
\text { and } \\
\text { Callender, } \\
\text { 1996) }\end{array}$ & $\begin{array}{l}\text { Trinity River } \\
\text { (this work) }\end{array}$ & $\begin{array}{l}\text { Galveston } \\
\text { Bay } \\
\text { (this work) }\end{array}$ \\
& \multicolumn{5}{c}{} \\
\hline $\mathrm{Fe}$ & 0.45 & 0.43 & - & 0.5 & 0.5 \\
$\mathrm{~Pb}$ & $3.0 \times 10^{-4}$ & $3.00 \times 10^{-4}$ & $3.50 \times 10^{-4}$ & $2.5 \times 10^{-4}$ & $6.0 \times 10^{-4}$ \\
$\mathrm{~V}$ & $1.4 \times 10^{-3}$ & $1.60 \times 10^{-3}$ & - & $1.2 \times 10^{-3}$ & - \\
$\mathrm{Cu}$ & $4.0 \times 10^{-4}$ & $3.00 \times 10^{-4}$ & $4.00 \times 10^{-4}$ & $4.0 \times 10^{-4}$ & $6.0 \times 10^{-4}$ \\
$\mathrm{Ni}$ & $4.0 \times 10^{-4}$ & $4.00 \times 10^{-4}$ & $5.00 \times 10^{-4}$ & $1.00 \times 10^{-3}$ & $1.0 \times 10^{-3}$ \\
$\mathrm{Zn}$ & $1.4 \times 10^{-3}$ & $1.20 \times 10^{-3}$ & $9.00 \times 10^{-4}$ & $1.0 \times 10^{-3}$ & $1.3 \times 10^{-3}$ \\
$\mathrm{Mn}$ & $1.0 \mathrm{E}-2$ & $1.20 \times 10^{-2}$ & - & $3.0 \times 10^{-2}$ & $2.5 \times 10^{-2}$ \\
$\mathrm{Si}$ & 5.5 & - & - & 1.9 & 2.0 \\
\hline
\end{tabular}

phases. Strong correlations were found between total metal concentration in suspended particles and the concentration of particulate Fe, which were similar, but not necessarily identical, during both transects, suggesting that these elements were associated with the Fe Fe-oxyhydroxide and/or sulfidic phase, which are enriched in the clay fraction (Fig. 10). During July 1995, Mn and $\mathrm{Cd}$ concentrations in suspended matter correlated with those of particulate Fe differently in two distinctive regions in Trinity Bay and the lower bay. Particulate Cd correlated significantly with particulate Mn for all Galveston Bay data points together rather than only in separate regions of the bay, as was observed for the correlation with particulate iron (Fig. 10), likely indicating that $\mathrm{Cd}$ was mainly controlled by the same process that controlled $\mathrm{Mn}$, namely the formation of Mn-oxyhydroxides. These correlations suggest that both Fe (oxides or sulfides) and Mn (oxides) could be equally important as a carrier phases for different metals. Despite different sampling times and different origins of particles (river borne or sea borne, benthic or pelagic), similar correlations of trace metals ( $\mathrm{Cu}, \mathrm{Ni}, \mathrm{Pb}, \mathrm{Zn}, \mathrm{Mn}$ ) with the carrier carrierphase metal (Fe) were found. These results suggest that the fate of these elements were to a large extent regulated by adsorption/desorption and coprecipitation mechanisms during the formation of oxyhydroxide and/or sulfide phases.

The concentrations of selected trace metals in dissolved $(>0.45 \mu \mathrm{m})$, colloidal ( $1 \mathrm{kDa} \sim 10 \mathrm{kDa}, 10 \mathrm{kDa} \sim 0.45 \mu \mathrm{m}, 1 \mathrm{kDa} \sim 0.45 \mu \mathrm{m}$ ), and truly dissolved $(<1 \mathrm{kDa})$ fractions were also measured during the same sampling trips (Wen et al., 1999). Trace metal concentrations in suspended particles were found to be both higher or lower than those in colloids, depending on the metal and the conditions. However, elemental ratios to $\mathrm{Fe}$ for $\mathrm{Cd}, \mathrm{Co}, \mathrm{Cu}$, $\mathrm{Ni}, \mathrm{Pb}, \mathrm{Zn}$, and $\mathrm{V}$ were significantly enriched in colloids over those in suspended particles (Table 5), suggesting that colloids are the main reason for the observed particle concentration effect (Table 3 ), as colloids are themselves exchanging with particulate phases. Because the suspended particle concentration in whole water is considerably greater than the colloids concentration (mass of solids per liter of water), metals associated with SPM ( $>0.45 \mathrm{um}$ ) still dominate the total metals concentration.
When comparing Me/Al (Table 4) and Me/Fe (Table 5) ratios for the Trinity River and Galveston Bay particles with those from average soils and sediments from upstream lakes (e.g., Lake Waco and Lake Livingston), the $\mathrm{Me} / \mathrm{Al}$ and $\mathrm{Me} / \mathrm{Fe}$ ratios for many metals (e.g., Fe, V, Co, Ni) in our study areas agreed, within a factor of 2, with those from world-average soils, except for $\mathrm{Cd}$, which was higher and $\mathrm{Si}$, which was lower in our study area.

Most metals are mostly present in the particulate rather than in the dissolved form, and thus, are retained in the estuary to a large extent $(\geq 70 \%$, Warnken and Santschi, in press). However, even though all particulate trace metals appear to significantly correlate with $\mathrm{Fe}$, and should be removed in the estuary together with particulate iron, of the metals in the filter-passing fraction, only Fe is mostly retained in Galveston Bay (Wen et al., 1999). All other dissolved (and colloidal) trace metals show additional fluxes to the ocean due to internal (sediment-water exchange) fluxes (Warnken et al., 2008; Warnken and Santschi, in press). The likely reason for this decoupling between Fe and associated metals could be the different pathways for colloidal and particulate Fe, whereby trace metals (except $\mathrm{Pb}$ ) are further fractionated from Fe during their passage through the estuary, likely related to autochthonous NOM formation and cycling.

\section{Conclusions}

The distributions of particulate trace elements in the middle of Galveston Bay, away from immediate pollution sources such as Houston, were characteristic in 1993 of a period when metals were controlled by relatively high fluxes from the Trinity River and when resuspension in the bay was minimal. In 1995, the metal distributions were controlled by a turbidity maximum (sediment resuspension) found in the upper bay region. Clay minerals originating from soil erosion likely served as a host phase for OC, Fe and Al rich phases, as is evident from the strong correlations between OC, Fe and Al in Trinity River particles. This correlation broke down for OC in Galveston Bay particles, however, likely due to the differential addition OC and/or removal of $\mathrm{Fe}$ and $\mathrm{Al}$ rich phases in the estuary. Little evidence for elevated trace metal concentrations in Trinity River and Galveston Bay particles was detected when average metal/Al or metal/Fe concentrations were compared to published ratios for world-average soils or uncontaminated environments in the Gulf of Mexico or other relatively pristine environments. The likely reason for these relatively low trace metal ratios here is the efficient removal of trace metals near pollution sources, e.g., behind the dam of Lake Livingston for the Trinity River (Warnken and Santschi, in press), and in the upper Houston Ship Channel near Houston (Wen et al., 1999).

Application of a selective leaching method to particulate trace metals in both the Trinity River and Galveston Bay samples

Table 5

Comparison of elemental ratios to OC and Fe for particles from Galveston Bay (GB) and the Trinity River (TR) with those of world-average soils (Li, 2000) and Galveston Bay colloids (Wen et al., 1996, 1997a,b, 1999)

\begin{tabular}{|c|c|c|c|c|c|c|}
\hline $\begin{array}{l}\text { Soil } \\
\text { element X }\end{array}$ & $\begin{array}{l}\text { Soil concentration } \\
(\mu \mathrm{g} / \mathrm{g})\end{array}$ & $\begin{array}{l}\text { Soil X/Fe } \\
\text { (wt. ratio) }\end{array}$ & $\begin{array}{l}\text { TR-particles } \\
\mathrm{X} / \mathrm{Fe} \text { (wt.) }\end{array}$ & $\begin{array}{l}\text { GB-particles } \\
\text { X/Fe (wt.) }\end{array}$ & $\begin{array}{l}\text { GB-colloids } \\
\text { X/Fe (wt.) }\end{array}$ & $\begin{array}{l}\text { GB-particles } \\
\text { X/OC (wt.) }\end{array}$ \\
\hline$\overline{\mathrm{Si}}$ & 325,000 & 11.1 & - & 4.5 & - & 1.6 \\
\hline OC & 20,000 & $6.8 \times 10^{-1}$ & 1.4 & 10 & $1 \times 10^{3}$ & 1 \\
\hline $\mathrm{Al}$ & 66,200 & 2.25 & 2.0 & 2.3 & $4 \times 10^{-1}$ & 0.5 \\
\hline $\mathrm{Cd}$ & 0.1 & $3.4 \times 10^{-6}$ & $1.0 \times 10^{-5}$ & $1.0 \times 10^{-5}$ & $6 \times 10^{-3}$ & $4 \times 10^{-6}$ \\
\hline Co & 13 & $4.4 \times 10^{-4}$ & $4.0 \times 10^{-4}$ & - & $3 \times 10^{-2}$ & - \\
\hline $\mathrm{Cu}$ & 23 & $7.8 \times 10^{-4}$ & $4.7 \times 10^{-4}$ & $6.0 \times 10^{-4}$ & $6 \times 10^{-1}$ & $1.4 \times 10^{-4}$ \\
\hline $\mathrm{Fe}$ & 29,400 & 1 & 1 & 1 & 1 & $2.5 \times 10^{-2}$ \\
\hline $\mathrm{Ni}$ & 27 & $9.2 \times 10^{-4}$ & $1.0 \times 10^{-3}$ & $1.0 \times 10^{-3}$ & $5 \times 10^{-1}$ & $2.7 \times 10^{-4}$ \\
\hline $\mathrm{Pb}$ & 25 & $8.5 \times 10^{-4}$ & $4.0 \times 10^{-4}$ & $6.0 \times 10^{-4}$ & $3 \times 10^{-2}$ & $1.4 \times 10^{-5}$ \\
\hline $\mathrm{Zn}$ & 74 & $2.5 \times 10^{-3}$ & $2.0 \times 10^{-3}$ & $3.0 \times 10^{-3}$ & $4 \times 10^{-1}$ & $7.4 \times 10^{-4}$ \\
\hline $\mathrm{Mn}$ & 580 & $2.0 \times 10^{-2}$ & $3.50 \times 10^{-2}$ & $4.0 \times 10^{-2}$ & $7 \times 10^{-1}$ & $1.1 \times 10^{-2}$ \\
\hline V & 83 & $2.8 \times 10^{-3}$ & $2.4 \times 10^{-3}$ & - & - & - \\
\hline
\end{tabular}


indicated that the majority of $\mathrm{Al}$ and $\mathrm{Fe}$, and major fractions of the other elements $(\mathrm{Cu}, \mathrm{Ni}, \mathrm{Pb}, \mathrm{Zn})$, were found in a refractory phase (L3), accessible only with strong acid treatment, thus indicating that silicate and/or pyritic phases are the main phases for these metals. Significant fractions of particle particle-reactive elements $(\mathrm{Mn}, \mathrm{Cd}, \mathrm{Pb})$ were also associated with a surface adsorbed phase (L1), and nutrient nutrient-type elements $(\mathrm{Cu}$, $\mathrm{Ni}, \mathrm{Zn}$ ) were more or less equally associated with surface adsorbed (L1) and reactive Fe-Mn (L2) carrier phases.

Fe could be used as a proxy for $\mathrm{Al}$ and/or OC, as concentrations of all three were strongly correlated for Trinity River particles. For Galveston Bay samples, particle-reactive elements such as $\mathrm{Pb}$ could be distinguished from nutrient-type elements such as $\mathrm{Cu}$, $\mathrm{Ni}$ and $\mathrm{Cd}$ using concentration ratios to Fe. Correlations of metal to Fe ratios with the Fe content of particles from Galveston Bay were found to be significant and positive for particle-reactive elements such as $\mathrm{Pb}$, but negative for nutrient-type elements such as $\mathrm{Cu}, \mathrm{Ni}$, and $\mathrm{Cd}$, while suspended particles from the Trinity River did not exhibit any such correlations at all, and only varied within a very limited range. This relative constancy is reflecting the composition of soils from its drainage basin as source materials. Indeed, ratios of different metals (e.g., $\mathrm{Co}, \mathrm{Cu}, \mathrm{Ni}, \mathrm{V}, \mathrm{Pb}$, $\mathrm{Zn}$, and $\mathrm{Mn}$ ) to Fe or $\mathrm{Al}$ in Trinity River particles were identical, within a factor of 2, to average soil ratios. In Galveston Bay waters, however, $\mathrm{Cu}$, along with $\mathrm{Ni}$ and $\mathrm{Cd}$, showed departures from the original soil composition, i.e., enrichments with respect to $\mathrm{Al}$ or Fe in samples with lower $\mathrm{Fe}$ (or $\mathrm{Al}$ ) or higher OC content, strongly suggesting imprints of the particle composition by autochthonous NOM formation as the cause of alterations in the particle composition rather than anthropogenic activities. Thus, it appears then that $\mathrm{Fe}$ and $\mathrm{Al}$ oxyhydroxide and/or silicate minerals are the primary phases that control trace metal distributions in the Trinity River, while freshly produced NOM can modify the trace metal content of the suspended particles in Galveston Bay.

\section{Acknowledgments}

We gratefully appreciate the assistance of Chris Paternostro, Ron Lehman, and Matt Quigley during the sampling expeditions to Galveston Bay, and Gary Gill for helpful suggestions during the initial phase of this work. We are also very grateful for the constructive and detailed comments of the reviewers and associate editor, which greatly improved the manuscript. This research was, in part, supported by grants from the Office of Naval Research (N00014-93-1-0877), the Texas Seagrant (424025) and the Texas Institute of Oceanography.

\section{References}

Abraham, J., 1998. Spatial distribution of major and trace elements in shallow reservoir sediments: an example from Lake Waco, Texas. Environ. Geol. 36 (3-4), 349-363.

Armstrong, N.E., 1982. Responses of Texas estuaries to freshwater inflows. Estuarine Comparisons 12, 103-120.

Audry, S., Blanc, G., Schäfer, J., Guerin, F., Masson, M., Robert, S., 2007. Budgets of $\mathrm{Mn}, \mathrm{Cd}$ and $\mathrm{Cu}$ in the macrotidal Gironde estuary (SW France). Mar. Chem. 107, 433-448.

Benoit, G., Rozan, T.F., 1999. The influence of size distribution on the particle concentration effect and trace metal partitioning in rivers. Geochim. Cosmochim. Acta 63, 113-127.

Benoit, G., Oktay-Marshall, S., Cantu, A., Hood, M., Coleman, C., Corapcioglu, O., Santschi, P.H., 1994. Partitioning of $\mathrm{Cu}, \mathrm{Pb}, \mathrm{Ag}, \mathrm{Zn}, \mathrm{Fe}, \mathrm{Al}$, and $\mathrm{Mn}$ between filter-retained particles, colloids and solution in six Texas estuaries. Mar. Chem. 44, 307-336.

Bruland, K.W., 1983. Trace elements in seawater. In: Riley, J.P., Chester, R. (Eds.), Chemical Oceanography, vol. 8. Academic Press, New York, pp. 157-220.

Buffle, J., 1990. Complexation Reactions in Aquatic Systems: an Analytical Approach. Ellis Horwood, New York, p. 336 pp.

Duinker, J.C., 1981. Partition of Fe, Mn, Al, K, Mg, Cu and $\mathrm{Zn}$ between particulate organic matter and minerals, and its dependance on total concentrations of suspended matter (in Holocene marine sedimentation in the North Sea basin). Spec. Publ. Int. Assoc. Sedimentol. 5, 451-459.

Duinker, J.C., Nolting, R.F., 1978. Mixing, removal and mobilization of trace metals in the Rhine River estuary. Netherlands J. Sea Res. 12, 205-233.

GBNEP - Galveston Bay National Estuary Program, The State of the Bay, 1994. A Characterization of the Galveston Bay Ecosystem. Galveston Bay National Estuary Program Publication GBNEP-44. 232 pp.

Guo, L., Santschi, P.H., 1997a. Composition and cycling of colloids in marine environments. Rev. Geophys. 35, 17-40.

Guo, L., Santschi, P.H., 1997b. Isotopic and elemental characterization of colloidal organic matter from the Chesapeake Bay and Galveston Bay. Mar. Chem. 59, 1-15.

Guo, L., Santschi, P.H., Warnken, K.W., 2000. Trace metal composition of colloidal material in estuarine and marine environments. Mar. Chem., 70, 257-275.

Guo, L., Tanaka, N., Schell, D.M., Santschi, P.H., 2003. Nitrogen and carbon isotopic composition of HMW dissolved organic matter in marine environments. Mar. Ecol. Prog. Ser. 252 (2003), 51-60.

Honeyman, B.D., Santschi, P.H., 1989. A Brownian-pumping model for trace metal scavenging: evidence from Th isotopes. J. Mar. Res. 47/4, 950-995.

Jiann, K.-T., 1993. Spatial and temporal variations in trace metal concentrations in sediments and oysters from Galveston Bay, Texas. Masters Thesis, Texas A\&M University, College Station, TX.

Jiann, K.-T., 1999. Trace Metals in Texas Rivers: A trace metal speciation study. Ph.D. Dissertation, Texas A\&M University, College Station, Texas.

Kersten, M., Forstner, U., 1986. Chemical fractionation of heavy metals in anoxic estuarine and coastal sediments. Water Sci. Technol. 18, $121-130$.

Kersten, M., Forstner, U., 1987. Effect of sample pretreatment on the reliability of solid speciation data on heavy metals-implications for the study of early diagenetic processes. Mar. Chem. 22, 299.

Koschinsky, A., Fritsche, U., Winkler, A., 2001. Sequential leaching of Peru Basin surface sediment for the assessment of aged and fresh heavy metal associations and mobility. Deep-Sea Res. II 48, 3683-3699.

Landing, W., Lewis, B., 1991. Analysis of marine particulate and colloidal material for transition metals. In: Hurd, D.C., Spencer, D.W. (Eds.), Marine Particles: Analysis and Characterization, AGU Geophysical Monograph Series. AGU, Washington, DC, pp. 263-272.

Li, Y.-H., 2000. A Compendium of Geochemistry. From Solar Nebula to the Human Brain. Princeton University Press, Princeton. 475 pp.

Lyven, B., Hassellov, M., Turner, D.R., Haraldsson, C., Andersson, K., 2003. Competition between iron- and carbon-based colloidal carriers for trace metals in a freshwater assessed using flow field-flow fractionation coupled to ICPMS. Geochim. Cosmochim. Acta 67 (20), 3791-3802.

Martin, J.M., Nirel, P., Thomas, A.J., 1987. Sequential extraction techniques: promises and problems. Mar. Chem. 22, 313-320.

Michalopoulos, P., Aller, R.C., 2004. Early diagenesis of biogenic silica in the Amazon delta: alteration, authigenic clay formation, and storage. Geochim. Cosmochim. Acta 68, 1061-1085.

Mondi, C., Leifer, K., Mavrocordatos, D., Perret, D., 2002. Analytical electron microscopy as a tool for accessing colloid formation process in natural waters. J. Microscopy 207, 180-190.

Morse, J.W., Presley, B.J., Taylor, R.J., Benoit, G., Santschi, P.H., 1993. Trace metal chemistry of Galveston Bay: water, sediments and biota. Mar. Environ. Res. 36, 1-37.

Novikov, A.P., Kalmykov, S.N., Utsunomiya, S., Ewing, R.C., Horreard, F., Merkulov, A., Clark, S.B., Tkachev, V.V., Myasoedov, B.F., 2006. Colloid transport of plutonium in the far-field of the Mayak production association, Russia. Science 314, 638-641.

O'Connor, D.J., Connolly, J.P., 1980. The effect of concentration of adsorbing solids on the partition coefficient. Water Res. 14, 1517-1526.

Rapin, F., Tessier, A., Campbell, P.G.C., Carignan, R., 1986. Potential artifacts in the determination of metal partitioning in sediments by a sequential extraction procedure. Environ. Sci. Technol 20, 836-840.

Robert, K.A., Santschi, P.H., Leppard, G.G., West, M., 2004. Characterization of organic-rich colloids from surface and ground waters at the actinidecontaminated Rocky Flats Environmental Technology Site (RFETS), Colorado, USA. Colloids Surf. A: Physicochem. Eng. Asp. 244, 105-111.

Salomons, W., Forstner, U., 1984. Metals in the Hydrocycle. Springer-Verlag, Berlin, p. 349.

Santschi, P.H., Lenhart, J., Honeyman, B.D., 1997. Heterogeneous processes affecting trace contaminant distribution in estuaries: the role of natural organic matter. Mar. Chem. 58, 99-125. 
Santschi, P.H., Roberts, K., Guo, L., 2002. The organic nature of colloidal actinides transported in surface water environments. Environ. Sci. Technol. 36, 3711-3719.

Shafer, M.M., Overdier, J.T., Hurley, J.P., Armstrong, D., Webb, D., 1997. The influence of dissolved organic carbon, suspended particulates, and hydrology on the concentration, partitioning and variability of trace metals in two contrasting Wisconsin watersheds (U.S.A.). Chem. Geol. 136, 71-97.

Shiller, A.M., Mao, L., 2000. Dissolved vanadium in rivers: effects of silicate weathering. Chem. Geol. 165, 13-22.

Summers, J.K., Wade, T., Engle, V., Malaeb, Z., 1996. Normalization of metal concentrations in estuarine sediments from the Gulf of Mexico. Estuaries 19, 581-594.

Taillefert, M., Lienemann, C.-P., Gaillard, J.-F., Perret, D., 2000. Speciation, reactivity, and cycling of $\mathrm{Fe}$ and $\mathrm{Pb}$ in a meromictic lake. Geochim. Cosmochim. Acta 64, 169-183.

Tang, D., Warnken, K.W., Santschi, P.H., 2001. Organic complexation of copper in surface waters of Galveston Bay. Limnol. Oceanogr. 46 (2), 321-330.

Tang, D., Warnken, K.W., Santschi, P.H., 2002. Distribution and partitioning of trace metals (e.g., Ni, Cu, Cd, Pb, Zn) in Galveston Bay waters. Mar. Chem. 78, 29-45.

Tessier, A., Campbell, P.G., Bisson, M., 1979. Sequential extraction procedure for the speciation of particulate trace metals. Anal. Chem. 51, 844-851.

Thompson, E.A., 1980. The effect of sample storage on the extraction of $\mathrm{Cu}, \mathrm{Zn}$, $\mathrm{Fe}, \mathrm{Mn}$, and organic material from oxidized estuarine sediments. Water Air Soil Pollut. 74, 215-233.

USGS - United States Geological Survey, 2007. USGS Water Data for Station \#08066500 Trinity River at Romayor, Texas, 2007. URL: http://tx. waterdata.usgs.gov.

Van Metre, P.C., Callender, E., 1996. Identifying water-quality trends in the Trinity River, Texas, USA, 1969-1992, using sediment cores from Lake Livingston. Environ. Geol. 28 (4), 190-200.

Warnken, K.W. 2002. Trace Metal Inputs to Galveston Bay: Importance of Benthic and Riverine Fluxes. Ph.D. Dissertation, Texas A\&M University, College Station, TX
Warnken, K.W., Santschi, P.H., 2004. Biogeochemical behavior of organic carbon in the lower Trinity River downstream of the Lake Livingston reservoir (Texas, USA). Sci. Total. Environ. 329, 131-144.

Warnken, K.W., Santschi, P.H., in press. Sediment and trace metal delivery from the Trinity River watershed to Galveston Bay and the Gulf of Mexico. Estuaries and Coasts.

Warnken, K.W., Gill, G.A., Griffin, L.L., Santschi, P.H., 2001. Sediment-water exchange of Mn, Fe, Ni and $\mathrm{Zn}$ in Galveston Bay. Texas. Mar. Chem. 73 , 215-231.

Warnken, K.W., Santschi, P.H., Roberts, K.A., Gill, G.A., 2008. The cycling and oxidation pathways of organic carbon in a shallow estuary along the Texas Gulf Coast. Estuar. Coast. Shelf Sci. 76, 69-84.

Wen, L.S., Santschi, P.H., Gill, G., Lehman, R., Paternostro, C., 1997a. Colloidal and particulate silver in river and estuarine waters of Texas. Environ. Sci. Technol. 31, 723-731.

Wen, L.S., Santschi, P.H., Tang, D., 1997b. Interactions between radioactively labeled colloids and natural particles: evidence for colloidal pumping. Geochim. Cosmochim. Acta 61 (14), 2867-2878.

Wen, L.S., Stordal, M.C., Tang D., Gill, G., Santschi, P.H., 1996. An ultraclean cross-flow ultrafiltration technique for the study of trace metal phase speciation in seawater. Mar. Chem. 55, 129-152.

Wen, L.S., Santschi, P.H., Paternostro, C., Gill, G., 1999. Estuarine trace metal distributions in Galveston Bay I: importance of colloidal forms in the speciation of the dissolved phase. Mar. Chem. 63 (3-4), 185-212.

Wen, L.S., Santschi, P.H., Gill, G., Tang, D., 2002. Silver concentrations in Colorado watersheds using improved methodology. Environ. Toxicol. Chem. 21 (10), 2040-2051.

Windom, H., Smith, R., Rawlinson, C., Hungspreugs, M., Dharmvanij, S., Wattayakorn, J., 1988. Trace metal transport in a tropical estuary. Mar. Chem. 24, 293-305.

Windom, H., Smith, R., Rawlinson, C., 1989. Particulate trace metal composition and flux across the southeastern U.S. continental shelf. Mar. Chem. 27, 283-297. 